\title{
Observations of hypervelocity boundary-layer instability
}

\author{
N. J. Parziale ${ }^{1,2, \dagger}$, J. E. Shepherd ${ }^{1}$ and H. G. Hornung ${ }^{1}$ \\ ${ }^{1}$ Graduate Aerospace Laboratories, California Institute of Technology, Pasadena, CA 91125, USA \\ ${ }^{2}$ Department of Mechanical Engineering, Stevens Institute of Technology, Hoboken, NJ 07030, USA
}

(Received 19 October 2014; revised 23 July 2015; accepted 18 August 2015; first published online 16 September 2015)

A novel optical method is used to measure the high-frequency (up to $3 \mathrm{MHz}$ ) density fluctuations that precede transition to turbulence within a laminar boundary layer in a hypervelocity flow. This optical method, focused laser differential interferometry, enables measurements of short-wavelength, high-frequency disturbances that are impossible with conventional instrumentation such as pressure transducers or hot wires. In this work, the T5 reflected-shock tunnel is used to generate flows in air, nitrogen and carbon dioxide with speeds between 3.5 and $5 \mathrm{~km} \mathrm{~s}^{-1}$ (Mach numbers between 4 and 6) over a $5^{\circ}$ half-angle cone at zero angle of attack. Simultaneous measurements are made at two locations approximately midway along a generator of the 1-m-long cone. With increasing Reynolds number (unit values were between 2 and $5 \times 10^{6} \mathrm{~m}^{-1}$ ), density fluctuations are observed to grow in amplitude and transition from a single narrow band of frequencies consistent with the Mack or second mode of boundary-layer instability to bursts of large-amplitude and spectrally broad disturbances that appear to be precursors of turbulent spots. Disturbances that are sufficiently small in initial amplitude have a wavepacket-like signature and are observed to grow in amplitude between the upstream and downstream measurement locations. A cross-correlation analysis indicates propagation of wavepackets at speeds close to the edge velocity. The free stream flow created by the shock tunnel and the resulting boundary layer on the cone are computed, accounting for chemical and vibrational non-equilibrium processes. Using this base flow, local linear and parabolized stability (PSE) analyses are carried out and compared with the experimental results. Reasonable agreement is found between measured and predicted most unstable frequencies, with the greatest differences being approximately $15 \%$. The scaling of the observed frequency with the inverse of boundary-layer thickness and directly with the flow velocity are consistent with the characteristics of Mack's second mode, as well as results of previous researchers on hypersonic boundary layers.

Key words: boundary layer stability, compressible boundary layers, compressible flows

\section{Introduction}

The study of boundary-layer transition from laminar to turbulent flow on high-speed vehicles has been the subject of ongoing research for over fifty years. This activity

$\dagger$ Email address for correspondence: nick.parziale@gmail.com 
is indicative of the difficult but potentially rewarding nature of these efforts. In the design of hypervelocity vehicles, the location of transition critically determines not only the drag, but also the degree to which thermal protection needs to be applied, because both friction and heating rate jump significantly at the transition point (Saric, Reed \& Kerschen 2002; Schneider 2004; Lau 2008; Lin 2008; Reshotko 2008; Schmisseur \& Erbland 2012). The receptivity and growth of the disturbances that precede transition within an initially laminar boundary layer in hypervelocity (characterized by speeds exceeding $3-4 \mathrm{~km} \mathrm{~s}^{-1}$ ) flow are less understood than in subsonic flows, particularly at conditions where gas dissociation and vibrational excitation must be considered. A better understanding of the receptivity and amplification process of disturbances in the boundary layer in this flight regime would enable more precise sizing of thermal protection systems, and facilitate hypervelocity vehicle optimization.

\subsection{Compressible boundary-layer instability}

There are many boundary-layer configurations and mechanisms of instability that are possible on vehicles. In the present study, we focus on the simplest configuration of a streamlined body and examine the flow associated with the development of a zero-pressure-gradient laminar boundary layer away from the leading edge or interference regions. Researchers have used the sharp flat plate and right-circular cone at zero angle of attack as the canonical geometry to study high-speed boundary-layer instability; in this work, we chose the latter. We make this choice because of the larger entropy layer 'swallowing length' associated with a sharp plate, which is in contrast to the shorter swallowing length associated with a sharp cone (Rotta 1966; Stetson 1983).

For a streamlined body in low-speed flight with an initially laminar boundary layer, the process of 'natural' transition (e.g. in a flow of very low free stream disturbance level) from laminar to turbulent flow is now a classical topic in fluid dynamics that is well understood. The instability theory of Tollmien (1929) and Schlichting (1933) of the growth of unstable modes ('T-S waves') prior to boundary-layer transition was experimentally verified by Schubauer \& Skramstad (1948), and subsequently has been the topic of numerous experimental, analytical and numerical studies. This is in contrast to the situation for high-speed flow with significant compressibility and thermal effects, where, despite the initial efforts of Lees \& Lin (1946), real progress did not occur until the discovery by Mack in the 1960s of multiple high-frequency instability modes that were confirmed in the experimental measurements by Kendall at JPL; see Mack (1999) for the history. The technical results of that first era of research, and the application to the prediction of supersonic boundary-layer transition are summarized in Mack (1975, 1984, 1999).

The high-frequency modes discovered by Mack are the dominant instability mechanism when the boundary-layer edge Mach number is sufficiently large, the angle of attack is small, and the wall temperature is sufficiently low compared to the recovery temperature; see the discussion and references in Bitter \& Shepherd (2014). Under these conditions the boundary layer features a region of supersonic flow relative to the phase velocity of disturbances, which acts as a waveguide and traps the disturbances within the boundary layer, leading to amplification (Fedorov 2011). Linear-stability theory predicts that waves of wavelength two to three times the boundary-layer thickness will propagate and amplify if the frequency is within a narrow range determined by the dispersion relation. A typical pattern of density 

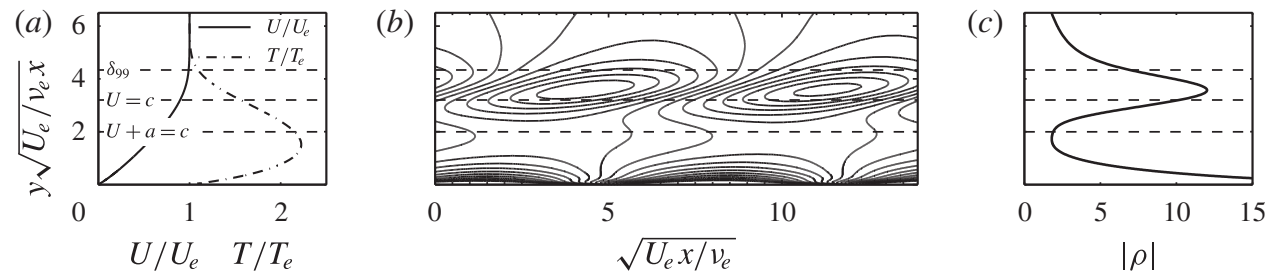

FIGURE 1. (a) Velocity and temperature profile in the boundary layer as a function of wall-normal distance $y$. Flow of nitrogen with $R e_{x}=1.83 \times 10^{6}, M a_{E}=5.93$, a cold $(300 \mathrm{~K})$ wall and a warm $(1014 \mathrm{~K})$ free stream. $(b)$ Contours of the real part of the density eigenfunction for a growing disturbance corresponding to Mack's second mode; this pattern propagates past a fixed measurement point $x$ with phase speed $c=0.9 U_{E}$ for this particular case. The eigenfunctions are normalized so that the amplitude of the pressure disturbance at the wall is unity. The location where the disturbance phase speed $c=U$ is known as the critical layer and the location $c=U+a$ ( $a$ being the local sound speed) is known as the disturbance relative sonic line. (c) Amplitude of density eigenfunction. These computations are based on locally parallel flow theory using the method of Mack for spatial instability (Bitter \& Shepherd 2014).

disturbances predicted by linear instability theory is shown in figure 1. This pattern convects with a velocity close to the edge value, and the spatial growth rate is inversely proportional to the boundary-layer thickness (Bitter 2015). The presence of these propagating disturbances can be measured by a variety of means, as discussed subsequently $(\S 2)$, and the analysis of the frequency content, propagation speed and amplitude can be used to experimentally characterize boundary-layer instability.

Mack termed the dominant higher-frequency mode the 'second mode', but Fedorov \& Tumin (2011) suggest 'that Mack's definitions of modes are inconsistent with conventional usage of the term normal modes'. Careful examination of the mode structure in the mathematical sense reveals that the instabilities arise from either fast or slow eigenmodes, as categorized by their phase speed at low frequency. However, most researchers continue to use the terminology 'second mode' to refer to the most rapidly growing of the Mack instability modes, to differentiate these from other possible boundary instabilities such as TS waves, crossflow, or transient-growth mechanisms. We will continue to use the historical terminology of 'second mode' in this paper.

\subsection{Hypervelocity flow}

Hypervelocity flows are distinguished by not only having a high Mach number $\left(M a_{E} \geqslant 5\right)$, but also having a flow velocity $U$ that is large enough so that significant vibrational excitation and dissociation can occur behind bow shocks and within boundary layers (Stalker 1989). These processes are known as 'real gas' or 'high-enthalpy' effects due to the magnitude of the mass-specific total enthalpy, $h_{0}=h+U^{2} / 2$ (Hornung 1993). The mass-specific total enthalpy plays a key role in the conversion of flow kinetic energy into thermal, vibrational and chemical energy in stagnation-like processes that exhibit a significant gradient in velocity (e.g. blunt-body flows, or slender-body viscous flows). For example, flows with $U=3 \mathrm{~km} \mathrm{~s}^{-1}$ and $6 \mathrm{~km} \mathrm{~s}^{-1}$ correspond to energies $\left(U^{2} / 2\right)$ of $4.5 \mathrm{MJ} \mathrm{kg}^{-1}$ and $18 \mathrm{MJ} \mathrm{kg}^{-1}$, respectively. The ability to achieve these energies is the principal 


\begin{tabular}{lccc} 
& $\mathrm{N}_{2}$ & $\mathrm{O}_{2}$ & $\mathrm{CO}_{2}$ \\
\hline$D\left(\mathrm{MJ} \mathrm{kg}^{-1}\right)$ & 33.6 & 15.4 & 6.3 \\
$E_{v}\left(\mathrm{MJ} \mathrm{kg}^{-1}\right)$ & 1.0 & 0.590 & 0.180
\end{tabular}

TABLE 1. Characteristic energy of dissociation $D$ and vibration $E_{v}$ (McQuarrie 2000).

advantage of using the reflected-shock tunnel with heated driver gas over conventional cold-flow hypersonic facilities.

The characteristic energies of dissociation $(D)$ and vibrational excitation $\left(E_{v}\right)$ for $\mathrm{N}_{2}, \mathrm{O}_{2}$ and $\mathrm{CO}_{2}$ are listed in table 1. For carbon dioxide, the dissociation reaction $\mathrm{CO}_{2} \rightarrow \mathrm{CO}+\frac{1}{2} \mathrm{O}_{2}$, and the lowest-energy (doubly degenerate) mode of vibrational excitation are considered. From these values, we see that significant vibrational excitation will occur for all of these molecules at and above $3 \mathrm{~km} \mathrm{~s}^{-1}$. At higher speeds the dissociation of oxygen and carbon dioxide will be significant. Nitrogen will remain primarily in the molecular form at speeds up to $6 \mathrm{~km} \mathrm{~s}^{-1}$ for typical test conditions simulating suborbital flight.

The influence of molecular vibrational excitation and dissociation on the transition from laminar to turbulent flow depends not only on the magnitude of the total enthalpy but also the rate of energy exchange between molecular processes and bulk motion. There are two possible effects: (1) the modification of the mean flow due to energy release or absorption modifying the temperature profile; and (2) the exchange of energy between the high-frequency second-mode instability of a hypersonic boundary layer and molecular vibrational relaxation or chemical relaxation processes. Linear-stability computations (Johnson, Seipp \& Candler 1998) indicate that endo- or exothermic chemical-thermodynamic processes affect the growth of small disturbances in the boundary layer. For this reason, we have examined three test gases, air, nitrogen and carbon dioxide, and a range of total enthalpy.

At sufficiently high Mach number there are also significant effects on the mean flow that can substantially influence the boundary-layer stability through the resulting mean temperature profile. Viscous dissipation results in the transformation of kinetic to thermal energy within the boundary layer, so the temperature within the boundary layer can be substantially higher than the free stream value. The shape of the temperature profile is a function of the boundary-layer edge conditions, the duration of the test, and the thermal properties of the model. The temperature-profile gradient at the model wall dictates whether a 'cold wall', 'adiabatic wall', or 'hot wall' experiment is being performed. For high-enthalpy short-duration experiments with a hot free stream, typical of reflected-shock or expansion tunnel testing, the model remains cold; so, the data reported herein are from cold-wall experiments. Calculations of the boundary-layer flow indicate that there is a pronounced temperature maximum within the boundary layer, as shown in figure 1. Stability computations (Mack 1975, 1984, 1999; Bitter \& Shepherd 2014; Bitter 2015) indicate that the shape of the mean temperature profile has a profound influence on the stability characteristics of the boundary layer. A cold wall stabilizes the first mode and destabilizes the second mode; at sufficiently high edge Mach number and wall cooling, the first mode is completely eliminated.

\section{Measurement of second-mode instability}

Measurements of the instability of the boundary layer on a sharp right-circular cone at zero angle of attack at hypersonic Mach numbers have been made with a number 
of measurement techniques. Kendall (1975), Demetriades (1977) and Stetson et al. (1983), Stetson, Donaldson \& Siler (1984), Stetson et al. (1989) appear to have made the first measurements of the Mack instability with hot-wire anemometry. Demetriades observed that the frequency of the instability, $f$, is proportional to the velocity at the boundary-layer edge, $U_{E}$, and inversely proportional to the boundary-layer thickness, $\delta: f=C U_{E} /(2 \delta)$, where the constant of proportionality is $0.6<C<0.9$. In Kimmel, Demetriades \& Donaldson (1996), extensive circumferential, streamwise, and wall-normal space-time correlations of detailed hot-wire anemometry data are used to characterize the structure of the instability waves. Hofferth et al. $(2013 a, b)$ recently carried out an extensive series of hot-wire measurements of mean flow and fluctuations within the boundary layer of a flared cone in a 'quiet flow' Mach 6 tunnel.

Commercial piezo-electric pressure transducers have been used recently by a number of investigators, mounting these flush with the surface of the test article to record wall-pressure fluctuations due to the boundary-layer instability. Fujii (2006) used pressure transducers placed along a generator of a $5^{\circ}$ half-angle cone to assess the effect of a wavy-wall roughness on the growth of the boundary-layer instability. Fujii et al. (2011) used surface-mounted pressure transducers to measure the second-mode instability and its growth rate along a generator of the cone; additionally, the nonlinear phase coupling of the disturbances was analysed by the bicoherence method. Casper (2009) and Berridge (2010) made hypersonic boundary-layer instability measurements with piezo-electric pressure transducers in a low-disturbance hypersonic facility. Typically, these measurements are limited to frequencies less than $300-500 \mathrm{kHz}$. The frequency response of the transducers is difficult to accurately characterize; although, the intrinsic resonant frequency of the transducers is quoted to be of the order of $1 \mathrm{MHz}$.

Fast-response heat-flux gauges have also been utilized to measure the high-frequency fluctuations in a hypersonic boundary layer. The atomic layer thermopile (ALTP) developed by Roediger et al. (2008) is claimed to have a frequency response of up to $1 \mathrm{MHz}$. Roediger et al. (2009) utilized ALTP gauges to measure the second-mode instability waves and compared the experimentally observed growth rates to growth rates calculated from linear-stability theory. Heitmann et al. (2011) used such heat-flux gauges to measure instabilities that were artificially excited in a hypersonic boundary layer.

For high-frequency measurements and locations within the boundary layer rather than on the model surface, optical methods are more promising than pressure or heat-flux transducers. A schlieren-based technique for the investigation of disturbances has been reported (Laurence et al. 2012; Laurence, Wagner \& Hannemann 2014a; Laurence et al. 2014b). In those reports, high-resolution and time-resolved images of the second-mode instability structure, along with valuable spectral and cross-correlation data are presented. Additionally, an optical technique based on a grid and lens style focused-schlieren technique was developed by Boedeker (1959) and refined by Weinstein (1993) and Garg \& Settles (1998). VanDercreek (2010) and VanDercreek, Smith \& Yu (2010) used this technique in their research, making measurements of the second-mode instability with the focused-schlieren deflectometer as well as with piezo-electric pressure transducers. Resonantly enhanced focused-schlieren measurements in T5 yielded some promising results (Parziale et al. 2011). Peaks in the spectral content at frequencies consistent with the Mack mode instability were found along with detection of turbulent bursts; however, the method of resonantly enhanced focused schlieren makes quantitative interpretation of the 
results difficult. Hofferth et al. $(2013 a, b)$ used the focused-schlieren technique to measure the second-mode waves in a low-disturbance wind tunnel.

Another very promising optical method is the two-beam laser differential interferometry (LDI) technique that was used to experimentally characterize gasdynamic flows by Smeets and George at the French-German Research Institute of Saint-Louis (ISL) in the 1970s (Smeets 1972, 1973, 1974, 1977; Smeets \& George 1973). The technique is sensitive to changes in optical path length that are related to density by the Gladstone-Dale relation. Smeets and George designed many variants of the two-beam differential interferometer, which were cleverly applied to demonstrate the potential of this approach in non-steady gas-dynamics, steady compressible aerodynamics, and acoustics.

Laderman \& Demetriades (1976) used the LDI method as a boundary-layer transition detection tool at Mach 3; they used a line-of-sight integrating LDI to detect increases in the RMS fluctuations in the boundary layer and related the increases in RMS fluctuation to transition to turbulence. Azzazy, Modarress \& Hoeft (1987) discusses the LDI as a turbulence detection tool in a shear layer, on a wind-tunnel wall at low subsonic Mach number, and in a Mach 2.36 boundary layer. They made measurements of transition in the shear layer and on the subsonic wind-tunnel wall, resolving low-frequency $(<100 \mathrm{kHz})$ spectral content. The LDI in O'Hare (1985) was a line-of-sight integrating set-up that imaged a shift in the fringe pattern formed on a wind-tunnel wall by two beams, one of which probed the hypersonic boundary layer on a slender cone, the other traversed the mean flow outside of the boundary layer. Frequencies in the range of the anticipated second-mode values were observed with the LDI, and were consistent with hot-wire anemometry, although the SNR was poor, and the frequency response appeared to be limited to less than $200 \mathrm{kHz}$. Salyer, Collicott \& Schneider (2006) used an LDI to make measurements in front of and behind the bow shock on a hemisphere for a hot spot generated by laser breakdown in a Mach 4 flow. Because the interest was in receptivity, all measurements were made outside the boundary layer.

It is significant that most of the previous efforts in measuring disturbances associated with the second-mode instability have been carried out in steady or quasi-steady flow facilities in relatively low vibration environments. The flows are typically relatively cold (low enthalpy) flows in which great attention (Schneider 2008) is paid to upstream flow quality and elimination of particulate matter in the flow, nozzle boundary-layer transition suppression, and, in general, efforts to make the tunnel as 'quiet' as possible. This is in contrast to the harsh mechanical environment of reflected-shock tunnels like T5. However, given the success of past efforts (Adam \& Hornung 1997; Germain \& Hornung 1997; Rasheed et al. 2002) in T5, as well as other researchers using shock tunnels (Tanno et al. 2009; Laurence et al. 2012, $2014 a, b)$ to study stability and transition, we felt confident that measurement solutions could be found.

\subsection{Focused laser differential interferometry}

Measurement of small-amplitude disturbances characteristic of the second-mode instability is a challenging task for a large-scale hypervelocity ground-test facility like T5. Considering the operation of the facility and the expected characteristics of the Mack mode disturbances, we identified six requirements for the instrumentation: (1) high sensitivity to small flow disturbances within the boundary layer; (2) high temporal resolution (>10 MHz); (3) high spatial resolution to resolve the small 


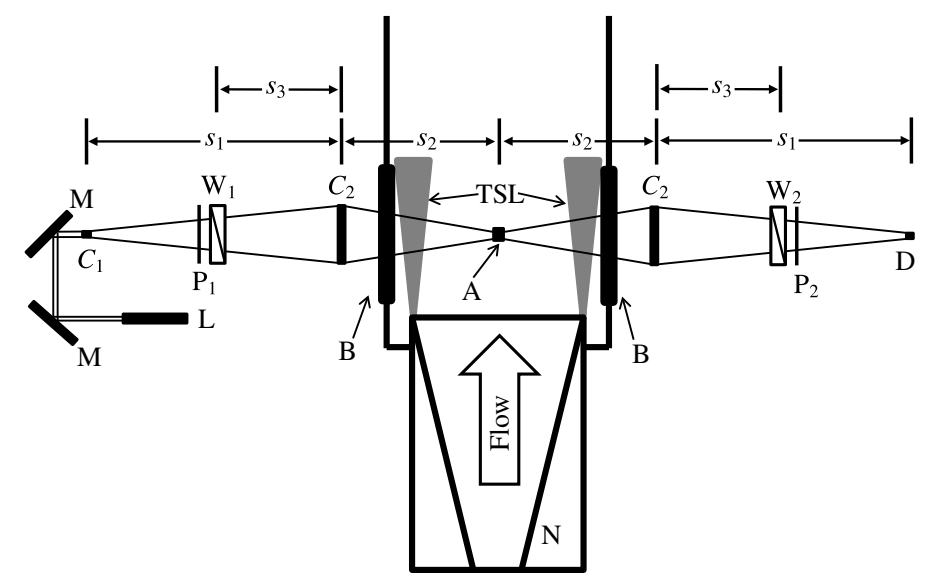

FIGURE 2. Annotated schematic of the FLDI. TSL, turbulent shear layer, L, Laser; M, mirror; $C_{1}, 10 \mathrm{~mm}$ focal length lens; $C_{2}, 300 \mathrm{~mm}$ focal length lens; P, polarizer; W, Wollaston prism (2 arc minutes); B, BK7 window; A, probe volume; D, photodetector; $\mathrm{N}$, nozzle, $s_{1}=718 \mathrm{~mm}, s_{2}=515 \mathrm{~mm}, s_{3}=300 \mathrm{~mm}$.

wavelength of the disturbance $(<1 \mathrm{~mm})$; (4) insensitivity to mechanical vibration; (5) the capability to have a small focal volume near the surface of the cone; and (6) a straightforward and repeatable means of extracting quantitative data. After experimenting with a number of techniques, Parziale, Shepherd \& Hornung (2013b, 2014) demonstrated that focused laser differential interferometry (FLDI) meets all these requirements.

The principle of the particular FLDI set-up used in the present study is to create two focal volumes within the boundary layer that are separated by a distance that is smaller than the wavelength of the density disturbance (figure 2). The key idea is to detect differences in optical path length due to the density differences at the two focal regions spatially separated in the streamwise direction. The other key distinguishing feature of the present set-up is that the optical paths of the light used to form the two focal volumes closely overlap except for a small region around the separated focal volumes. The geometry of the light paths ensures the localization of the probe volume, and rejection of disturbances common to both paths. The high speed of measurement is due to the intrinsic high-frequency response of the electro-optical detectors and recording equipment. All of these features were key to enabling the measurements under T5 conditions.

The laser used in this experiment is a Spectra-Physics Excelsior diode pumped solid state continuous-wave laser (532 nm wavelength, $200 \mathrm{~mW}$ power). The high-quality beam $\left(\mathrm{TEM}_{00}\right)$ does not require additional beam conditioning for use as an interferometer. A schematic of the optical set-up is presented in figure 2 . The response of the photodetector $(22.5 \mathrm{~V}$ battery biased FDS100 photodiode) is amplified at a gain of 25 (SRS SR445) and digitized at $100 \mathrm{MHz}$ by a 14-bit Ethernet oscilloscope (Cleverscope CS328A-XSE); all leads are terminated at $50 \Omega$.

A relationship between the fluctuations in density and output voltage from the photodetector is required for interpreting the FLDI output, and is determined (Parziale et al. 2013b) to be

$$
\frac{\Delta \rho}{\rho_{L}}=\frac{\lambda_{0}}{2 \pi K L \rho_{L}} \sin ^{-1}\left(\frac{V}{V_{0}}-1\right) .
$$


This relation is found by considering the variations in optical phase along the beam direction, $z$, and considering the FLDI as a two-beam differential interferometer. Here, $\Delta \rho / \rho_{L}$ is the difference in density traversed by the sensitive probe volumes normalized by the local average density. The laser wavelength is $\lambda_{0}, K$ is the Gladstone-Dale constant, $V$ is the instantaneous photodetector voltage, $V_{0}$ is the photodetector voltage at the middle of an interference fringe, and $L$ is the sensitive length. The sensitive length was determined to be approximately $\pm 10 \mathrm{~mm}$ from the beam focus. This was found by utilizing a steady $\mathrm{CO}_{2}$ jet as a control, and traversing a distance from the beam focus to determine the point at which the response is decreased by $1 / e$ from the centreline value (Parziale, Shepherd \& Hornung 2013a; Parziale 2013). Additionally, spherical acoustic pulses were created by focusing a $200 \mathrm{~mJ} 532 \mathrm{~nm}$ Nd:YAG laser to ionize a small volume of gas equidistant from the upstream and downstream detectors. The difference in peak response for properly aligned systems is less than $3.5 \%$, bringing confidence to the repeatability of the experiment. This testing procedure is repeated approximately every $20 \mathrm{~T} 5$ shots, or when the results from the previous T5 shot indicate misalignment (Parziale et al. 2013a; Parziale 2013).

The two beams are spaced $350 \mu \mathrm{m}$ apart in the streamwise direction, and the phase object is integrated over the optical path length $L$. It is clear that some averaging of the density variations across the boundary layer will take place due to the finite width of the sensitive volume in the spanwise direction. However, due to the two-dimensional nature of the Mack modes (Mack 1975, 1984, 1999) and the rapid decrease in detection sensitivity with increasing transverse distance from the focal point, the average density difference is highly weighted towards the values near the focal volumes.

For each individual T5 test, the wall-normal distance from the surface of the cone to the volume being probed by the FLDI is measured with a dial-indicator, translating a razor-blade cutoff normal to the surface of the cone. Wall-normal distances range from $450-990 \mu \mathrm{m}$, and the uncertainty is estimated to be $\pm 50 \mu \mathrm{m}$; this is the calculated beam diameter, which is noted to be twice the precision of the dial-indicator. The wallnormal distance is chosen to be approximately $60 \%$ of the predicted boundary-layer thickness at each probe-volume location. There were two FLDI probe volumes used to simultaneously measure the instability at two locations within the boundary layer; they were located $627 \pm 1 \mathrm{~mm}$ and $718 \pm 1 \mathrm{~mm}$ from the cone tip along a single cone generator.

The systematic error stemming from applying (2.1) to the raw data is found by considering the propagation of uncertainty in $\Delta \rho / \rho_{L}$ as a function of all the input parameters, assuming that they are independent of each other (Coleman \& Steele 1999). The error in $\Delta \rho / \rho_{L}$ is approximately $20 \%$. Details of the error analysis are reported in Parziale et al. $(2013 b)$.

\section{T5 testing and results}

A series of tests in the T5 reflected-shock tunnel are carried out to measure the incipient instability waves prior to the transition to fully turbulent flow on a right-circular cone at zero angle of attack. The $5^{\circ}$ half-angle cone is constructed of aluminium and instrumented with an array of flush-mounted fast-response thermocouples used as heat-flux gauges; the heat-flux gauges are used to determine the transition location, as determined by the departure from calculated laminar heating rate. The cone has a surface roughness of less than $5 \mu \mathrm{m}$ and has a replaceable 
molybdenum tip that has a radius estimated to be $400 \mu \mathrm{m}$; after a break-in period for a new tip, this radius remains essentially constant during the testing series. The slightly blunt tip produces a bow shock, resulting in the boundary layer initially developing within the hot, high-entropy fluid layer downstream of the bow shock. In the flow over a cone, the entropy layer decreases with downstream distance until it is eventually 'swallowed' by the boundary layer. Following Rotta (1966) and Stetson (1983), the 'swallowing' distance is calculated to be no more than $90 \mathrm{~mm}$ from the cone tip for any run condition presented in this work. This distance is less than $15 \%$ of the distance to the upstream FLDI probe volume; therefore, the cone is idealized as 'sharp' for the purposes of analysing the outer flow and the boundary layer at the probe-volume locations.

The tunnel operation and data analysis are described in detail by Parziale (2013). Briefly, the shock tunnel uses an air-driven piston to create hot, high-pressure driver gas to rupture the primary diaphragm and produce a strong shock wave in the test gas. The reflection of the shock at the end of the shock tube generates the high-enthalpy reservoir used to supply a converging-diverging nozzle; quasi-steady flow in the nozzle creates the hypervelocity flow over the cone model located near the nozzle exit. The noise level in the free stream flow is characterized using single-point FLDI density fluctuation measurements in the free stream, as discussed in Parziale et al. (2014). The typical RMS fluctuation intensity is less than $0.5 \%$ for disturbance wavelengths between 0.7 and $10 \mathrm{~mm}$, the range relevant to direct excitation of second-mode instabilities in our study. The fluctuation intensity is higher (up to $5-7 \%$ ) at longer wavelengths, up to $100 \mathrm{~mm}$, which may be relevant to various receptivity mechanisms; a review of nonlinear breakdown processes in hypersonic boundary layers can be found in Zhong \& Wang (2012).

A range of flow conditions can be generated at the nozzle exit by varying the gas composition and fill pressures in the shock tube and driver, as well the primary diaphragm rupture pressure. Relying on an extensive database from past operation and calibration of the tunnel performance, the flow Reynolds number and location of transition to turbulence on the cone model can be adjusted so that repeatable observations can be made of the onset and growth of instabilities in an initially laminar boundary layer. The location of boundary-layer transition is identified by departure from laminar surface heat-flux rates measured by surface-mounted heat-transfer gauges, as discussed in Jewell et al. (2011, 2012), Jewell, Shepherd \& Leyva (2013a), Jewell et al. (2013b) and Jewell (2014). Operating conditions for T5 are selected on the basis of these heat-flux measurements and, more importantly, the FLDI measurements provided a clear indication of the nature of the flow at those measurement locations. Through careful selection of conditions and cleaning of the shock tube, it is possible to systematically prescribe transition locations that are estimated to correspond to second-mode amplification factors $e^{N}$ of $N \approx 8-12$ (Jewell et al. 2013a,b; Jewell 2014). These amplification values are high as compared to the more typical value of $N \approx 5-6$ usually characterizing a 'noisy' tunnel (Schneider 2001), but consistent with the expected difference in receptivity for the high-frequency second-mode instability as compared to the relatively low-frequency noise in the T5 free stream as measured by Parziale et al. (2014). This is supported by the recent analysis of Gronvall, Johnson \& Candler (2014), who found a transition onset value of $N \sim 8$ for the shock-tunnel experiments of Tanno et al. (2009).

For each test, the flow conditions at the outer edge of the boundary layer are computed using measured tunnel data and numerical simulation of the shock reflection process, flow through the nozzle, and over the cone model. The measured 


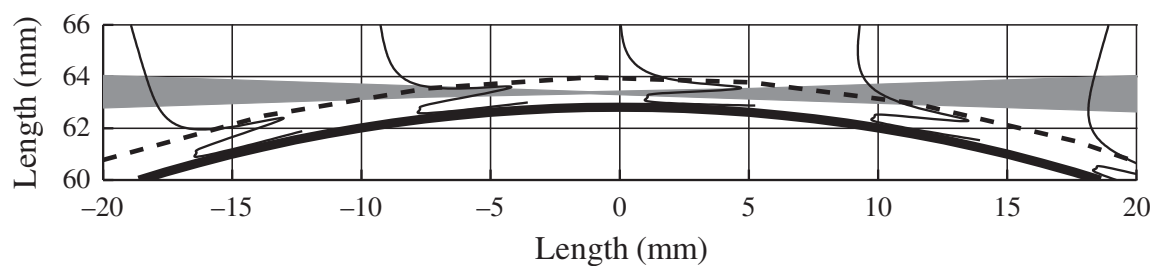

FIGURE 3. Overlay of cone surface (solid thick line), calculated boundary-layer thickness for shot 2789 (dashed line), density eigenfunction for shot 2789 (solid thin lines), and laser beam profile (grey filled area). The zero of the abscissa is the focus of the beam. The cone tip is located out of the page.

shock speed and reflected-shock pressure are used to obtain the conditions in the reservoir following shock reflection based on equilibrium thermochemistry, the shock jump conditions, and assuming isentropic expansion of the gas at the end wall to the pressure measured during the test time. An accurate geometric model of the converging-diverging nozzle is used to compute the steady expansion of the reservoir gas, including real gas effects through an excluded volume model, as described by Candler (2005). Averaged conditions on the centreline of the nozzle at the cone tip are used as the input to compute the viscous flow over the cone. Both the nozzle and cone flow simulations assume axisymmetric viscous flow, and include chemical reaction and vibration-translational rate processes. The computations were carried out with the STABL software suite, which uses a data-parallel lower-upper relaxation (DPLR) method, as described by Wright, Candler \& Prampolini (1996), Johnson et al. (1998), and Johnson (2000).

\subsection{FLDI measurements}

Two FLDI measurement volumes, located within the boundary layer (figure 3) and upstream of the transition location, are used to simultaneously measure time-resolved density fluctuations. Representative principal signatures observed in FLDI signals are shown in figure 4 . The signal in $(a)$ represents a large-amplitude, broad-band disturbance that is associated with locally turbulent flow, whereas that in $(b)$ represents a small-amplitude, narrow-band disturbance in otherwise laminar flow. We will refer to these distinct signatures in subsequent descriptions of experimental results. We interpret the large-amplitude signature $(a)$ as corresponding to the passage of a turbulent spot past the measurement location. The small-amplitude signature (b) corresponds to the passage of a second-mode wavepacket.

Results of the FLDI time series measurements are analysed in terms of frequency content, coherence of upstream and downstream disturbances, and the change in disturbance amplitude between the two locations. Measurements were made in air for two ranges of total enthalpy, in nitrogen for three ranges of total enthalpy, and in carbon dioxide for one range of total enthalpy. The results for air are presented in detail, and the results for the $\mathrm{N}_{2}$ and $\mathrm{CO}_{2}$ are described more briefly, as the measured spectral content was qualitatively similar for all test gases. In addition to the FLDI measurements, high-speed video recording of the density disturbances are made for selected cases.

There are two series of air tests, described in table 2 as 'low enthalpy' (5-9 $\mathrm{MJ} \mathrm{kg}^{-1}$ ) and 'high enthalpy' (11-13 $\left.\mathrm{MJ} \mathrm{kg}^{-1}\right)$. The rapid expansion in the shock-tunnel nozzle 


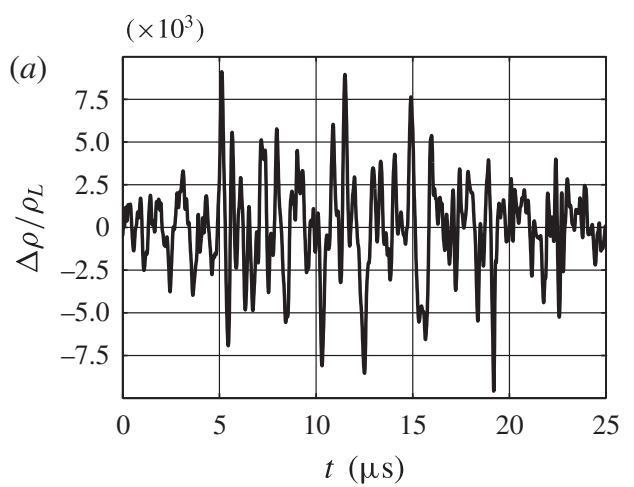

(b)

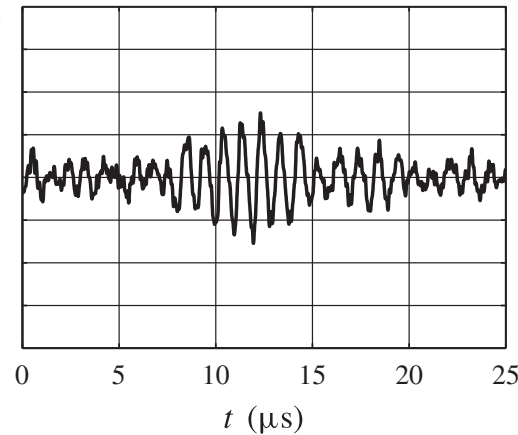

FIGURE 4. Examples of the two principal signatures observed in FLDI signals: $(a)$ broadband, large-amplitude signal characteristic of locally turbulent flow; $(b)$ narrow-band, smallamplitude signal, characteristic of a wavepacket in laminar flow. These examples are for an air boundary layer (shot 2743) with $h=9.1 \mathrm{MJ} \mathrm{kg}^{-1}$.

\begin{tabular}{|c|c|c|c|c|c|c|c|c|c|c|c|}
\hline Shot & $\begin{array}{c}U_{E} \\
\left(\mathrm{~m} \mathrm{~s}^{-1}\right)\end{array}$ & $\begin{array}{c}\rho_{E} \\
\left(\mathrm{~kg} \mathrm{~m}^{-3}\right)\end{array}$ & $\begin{array}{c}P_{E} \\
(\mathrm{kPa})\end{array}$ & $\begin{array}{l}T_{t / r E} \\
(\mathrm{~K})\end{array}$ & $\begin{array}{l}T_{v E} \\
(\mathrm{~K})\end{array}$ & $\begin{array}{l}M a_{E} \\
(-)\end{array}$ & $\begin{array}{l}\operatorname{Re}_{E}^{\text {Unit }} \\
\left(\mathrm{m}^{-1}\right)\end{array}$ & $\begin{array}{l}Y_{\mathrm{N}_{2}} \\
(-)\end{array}$ & $\begin{array}{l}Y_{\mathrm{O}_{2}} \\
(-)\end{array}$ & $\begin{array}{l}Y_{\mathrm{NO}} \\
(-)\end{array}$ & $\begin{array}{l}Y_{\mathrm{O}} \\
(-)\end{array}$ \\
\hline \multicolumn{12}{|c|}{ Low enthalpy } \\
\hline 2767 & 3728 & 0.029 & 12.7 & 1505 & 1343 & 4.72 & $1.98 \times 10^{6}$ & 0.73 & 0.17 & 0.07 & 0.02 \\
\hline 2766 & 3464 & 0.033 & 12.1 & 1248 & 1095 & 4.85 & $2.36 \times 10^{6}$ & 0.73 & 0.18 & 0.08 & 0.01 \\
\hline 2765 & 3248 & 0.038 & 11.5 & 1039 & 900 & 5.00 & $2.82 \times 10^{6}$ & 0.73 & 0.19 & 0.08 & 0.01 \\
\hline 2764 & 2982 & 0.037 & 8.3 & 776 & 725 & 5.33 & $2.99 \times 10^{6}$ & 0.73 & 0.19 & 0.07 & 0.00 \\
\hline \multicolumn{12}{|c|}{ High enthalpy } \\
\hline 2788 & 4425 & 0.067 & 46.1 & 2322 & 2281 & 4.49 & $4.03 \times 10^{6}$ & 0.74 & 0.16 & 0.07 & 0.03 \\
\hline 2789 & 4244 & 0.076 & 47.1 & 2105 & 2062 & 4.55 & $4.73 \times 10^{6}$ & 0.73 & 0.17 & 0.07 & 0.02 \\
\hline 2790 & 4199 & 0.079 & 47.3 & 2046 & 2001 & 4.57 & $4.94 \times 10^{6}$ & 0.73 & 0.17 & 0.07 & 0.02 \\
\hline 2787 & 4062 & 0.079 & 43.2 & 1878 & 1819 & 4.63 & $5.08 \times 10^{6}$ & 0.73 & 0.18 & 0.07 & 0.02 \\
\hline
\end{tabular}

TABLE 2. Air boundary-layer edge conditions.

results in boundary-layer edge conditions that are slightly out of equilibrium due to the 'freezing' of both chemical reactions and exchange of energy between vibrational modes of molecular motion and the translational and rotational modes. This results in the effective translational-rotational temperature $T_{t / r E}$ being slightly $(50-150 \mathrm{~K}$ ) lower than the effective vibrational temperature $T_{v E}$. The air is highly dissociated upstream of the shock-tunnel nozzle, and the freezing of the recombination reactions during flow through the nozzle results in a significant (7-8\%) non-equilibrium concentration of NO and a smaller (1-2\%) amount of $\mathrm{O}$, as indicated by the mass fractions $Y_{\mathrm{NO}}$ and $Y_{\mathrm{O}}$. The same nozzle is used for all tests so that the edge Mach number $M a_{E}$ is nearly constant for the low enthalpy and high enthalpy test series, varying because of thermochemical and real gas effects, resulting in slightly off-design operation that depends on the particular conditions of each case.

In each series, the unit Reynolds number $\left(R e_{E}^{\text {Unit }}\right)$ is evaluated at the boundary-layer edge, and decreases when the reservoir pressure is held nominally constant and 

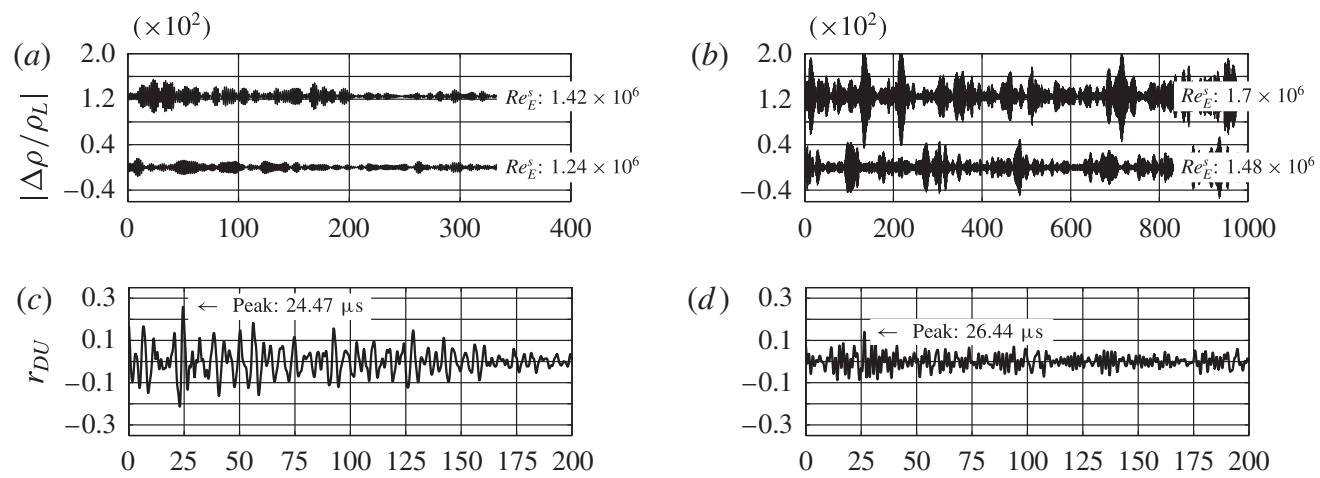

(d)
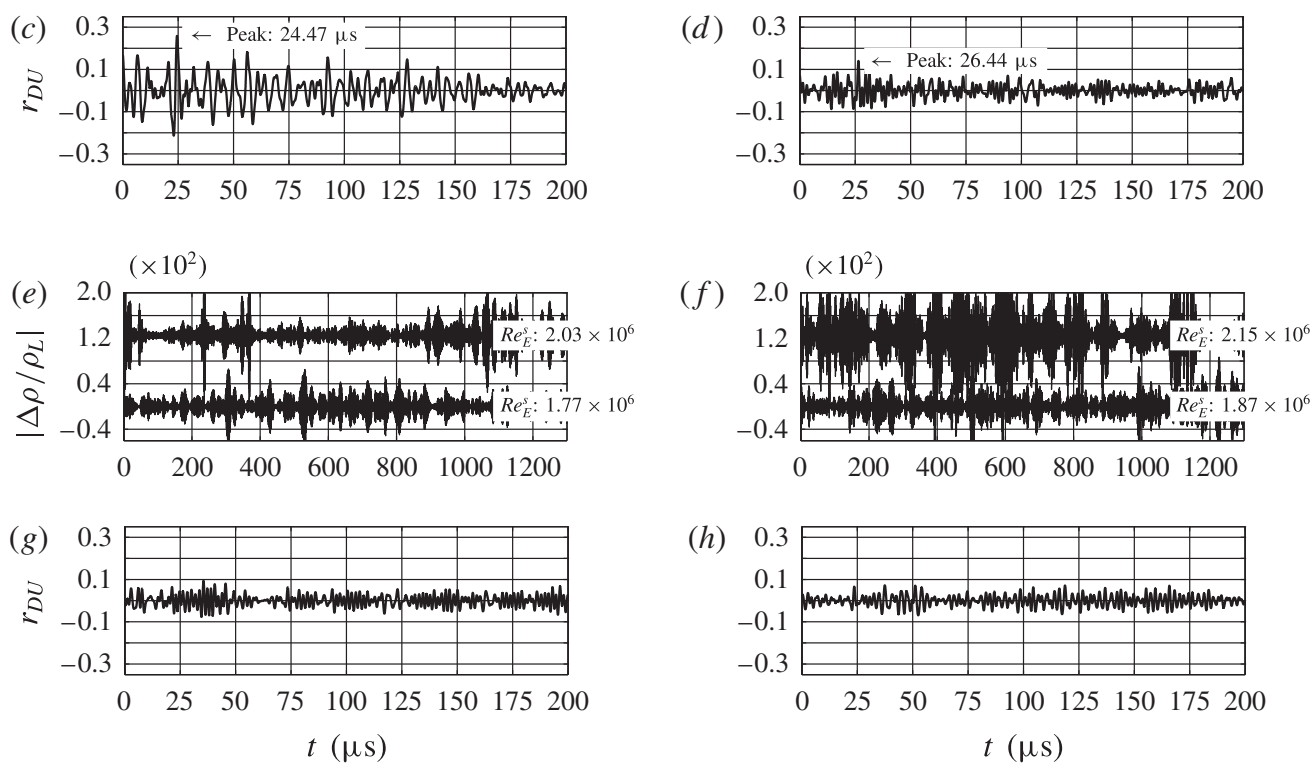

(h)

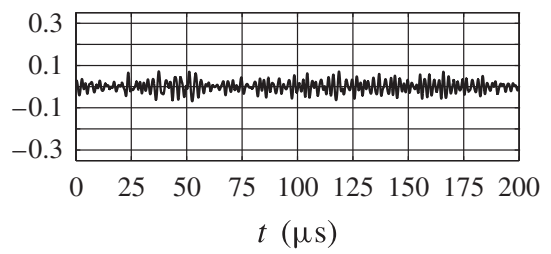

Figure 5. $(a, b, e, f)$ Time traces and $(c, d, g, h)$ cross-correlations of $\Delta \rho / \rho_{L}$ for the low-enthalpy air test series (conditions summarized in table 2). In order of increasing unit Reynolds number: (a,c) Shot $2767-R e_{E}^{\text {Unit }}=1.98 \times 10^{6} \mathrm{~m}^{-1} ;(b, d)$ Shot $2766-R e_{E}^{\text {Unit }}=2.36 \times 10^{6} \mathrm{~m}^{-1} ;(e, g)$ Shot $2765-R e_{E}^{\text {Unit }}=2.82 \times 10^{6} \mathrm{~m}^{-1} ;(f, h)$ Shot 2764: $R e_{E}^{\text {Unit }}=2.99 \times 10^{6} \mathrm{~m}^{-1}$.

the reservoir enthalpy is increased. This leads to the somewhat counterintuitive result that in order to move the transition location forward under constant reservoir pressure conditions, the reservoir enthalpy is lowered. The primary difference in edge conditions between low- and high-enthalpy tests is the magnitude of the edge flow speed and temperature - both are increasing functions of reservoir enthalpy. In order to compensate for the decrease in Reynolds number with increasing reservoir enthalpy, and obtain transition at similar physical locations in both series of tests, the reservoir pressure was adjusted to be higher in the high-enthalpy series than in the low-enthalpy series. The high-enthalpy cases have boundary layers that are approximately $60 \%$ thinner than for the low-enthalpy cases. Thinner boundary layers combined with higher edge speeds result in second-mode frequencies that are approximately twice as high for the high-enthalpy as compared to low-enthalpy cases.

\subsubsection{Low-enthalpy conditions}

Segments of time series of non-dimensional fluctuations in density $\left(\Delta \rho / \rho_{L}\right)$ at both probe volumes and cross-correlation of the upstream and downstream signals are shown in figure 5 for four values of unit Reynolds number. These signals have 


\begin{tabular}{ccccccccccc} 
Shot & $\begin{array}{c}M a_{E} \\
(-)\end{array}$ & $\begin{array}{c}U_{E} \\
\left(\mathrm{~m} \mathrm{~s}^{-1}\right)\end{array}$ & $\begin{array}{c}\tau \\
(\mu \mathrm{s})\end{array}$ & $\begin{array}{c}U_{E} /(\Delta s / \tau) \\
(-)\end{array}$ & $\begin{array}{c}\delta_{U} \\
(\mathrm{~mm})\end{array}$ & $\begin{array}{c}f_{U} \\
(\mathrm{kHz})\end{array}$ & $\begin{array}{c}2 f_{U} \delta_{U} / U_{E} \\
(-)\end{array}$ & $\begin{array}{c}\delta_{D} \\
(\mathrm{~mm})\end{array}$ & $\begin{array}{c}f_{D} \\
(\mathrm{kHz})\end{array}$ & $\begin{array}{c}2 f_{D} \delta_{D} / U_{E} \\
(-)\end{array}$ \\
\hline & & & & \multicolumn{7}{c}{ Low enthalpy } \\
2767 & 4.72 & 3728 & 24.5 & 1.00 & 1.91 & 620 & 0.63 & 2.04 & 580 & 0.63 \\
2766 & 4.85 & 3464 & 26.4 & 1.00 & 1.77 & 620 & 0.63 & 1.89 & 580 & 0.63 \\
2765 & 5.00 & 3248 & - & - & 1.67 & 580 & 0.64 & 1.79 & - & - \\
2764 & 5.33 & 2982 & - & - & 1.72 & - & - & 1.84 & - & - \\
& & & & & High enthalpy & & & & \\
2788 & 4.49 & 4425 & - & - & 1.25 & - & - & 1.34 & - & - \\
2789 & 4.55 & 4244 & 20.5 & 0.96 & 1.17 & 1200 & 0.66 & 1.25 & 1180 & 0.69 \\
2790 & 4.57 & 4199 & - & - & 1.14 & 1200 & 0.65 & 1.22 & - & - \\
2787 & 4.63 & 4062 & - & - & 1.14 & - & - & 1.22 & - & -
\end{tabular}

TABLE 3. Air boundary-layer instability parameters and scaling.

been band-pass filtered to remove low- and high-frequency noise; the frequency band has been selected to bracket the range of frequencies characterizing second-mode instabilities. The density fluctuations shown in figure 5 increase in amplitude between the upstream (lower signal) and downstream locations (upper signal), and the RMS signal level at both locations increases with increasing unit Reynolds number. Although details of the waveforms shown in figure 4 cannot be observed in figure 5 due to the much longer time scale, it is clear that the signals are made up of 'bursts' occurring at irregular intervals, characteristic of fluctuations observed in flows near the onset of turbulence.

The cross-correlations in figure 5 are normalized by the square root of the product of the auto-covariances at zero lag, so that the maximum correlation value is unity. A distinct correlation peak near $25 \mu \mathrm{s}$ can be observed for the two low-Reynolds-number cases, figure $5(a, c)$ and $(b, d)$. A pronounced peak in cross-correlation is observed when both the upstream and downstream signals show the low-amplitude, wavepacket-like signature of figure $4(b)$. The time $\tau$ corresponding to the peak in the cross-correlation is within $5 \%$ (table 3) of the time $\Delta s / U_{E}$, where $U_{E}$ is the boundary-layer edge velocity and $\Delta s$ is the distance between the detector locations. This suggests that the detectors are tracking wavepackets that are travelling along the generator of the cone at approximately the edge velocity. Further examination of the signals shows that the well-defined peak in the cross-correlation occurs only when both detectors have a distinct narrow-band spectral response corresponding to signals composed primarily of wavepackets of the type in figure $4(b)$. No well-defined cross-correlation peak is observed in either figure $5(e, g)$ or $(f, h)$, as the downstream detector signals consist primarily of broad-band disturbances with the signature of figure $4(a)$.

The conclusions regarding the spectral characteristics of the signals are quantitatively demonstrated by the estimates of the power spectral density (PSD) shown in figure 6 for the signals displayed in figure 5. These are computed using Welch's method, with $50 \%$ overlapping $20 \mu \mathrm{s}$ Hann windows. For the lowest Reynolds number cases, figure $6(a, b)$, distinct peaks corresponding to the wavepackets occur near a frequency of $600-700 \mathrm{kHz}$ and are observed on both the upstream and downstream detectors. The peak frequency is slightly lower for the downstream signal than the upstream signal. As discussed subsequently, this is due to the increasing thickness of the 

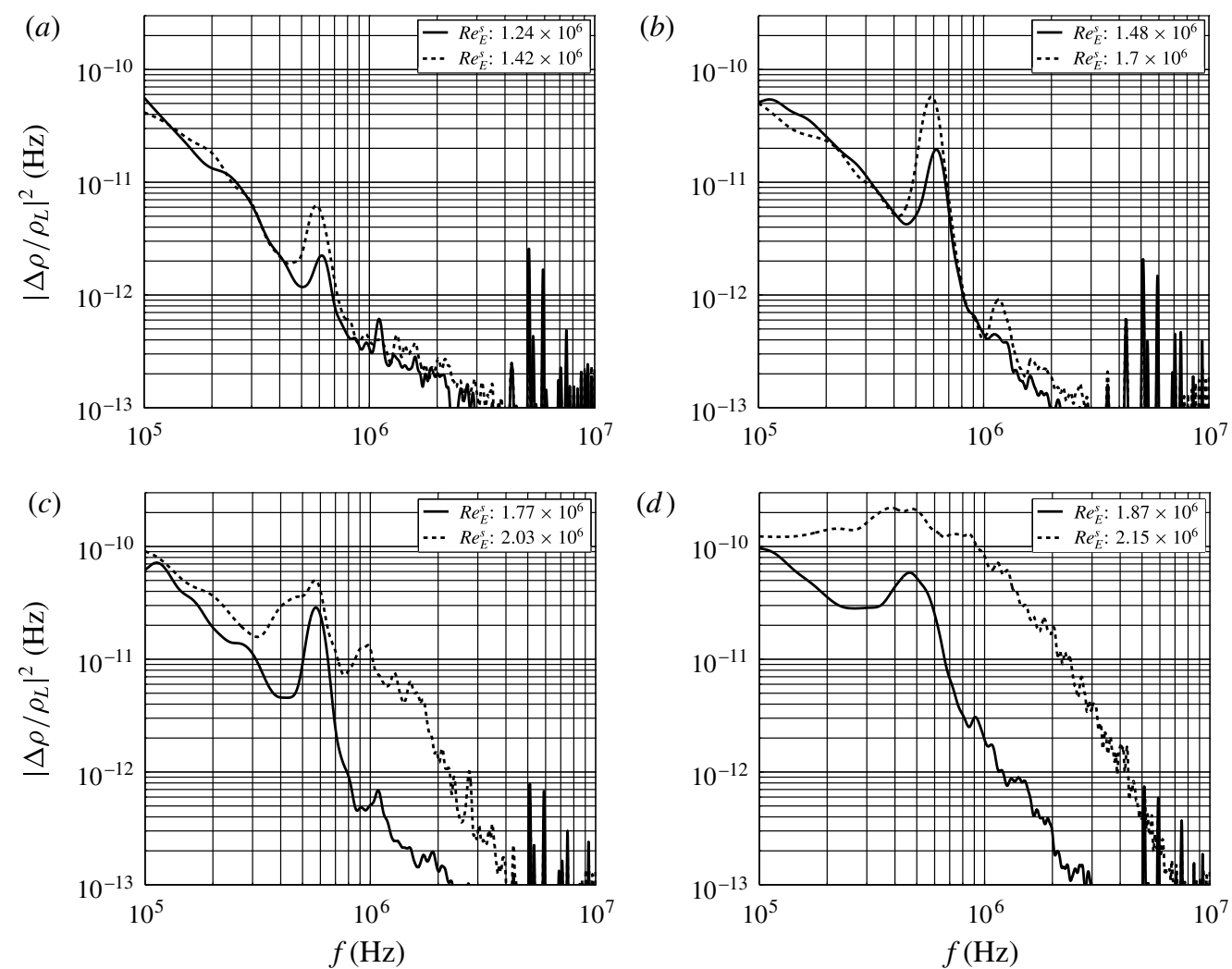

FIgURE 6. Power spectral density estimates of $\Delta \rho / \rho_{L}$ for the low-enthalpy air shot series (conditions summarized in table 2). In order of increasing unit Reynolds number: $(a)$ shot $2767-R e_{E}^{\text {Unit }}=1.98 \times 10^{6} \mathrm{~m}^{-1} ;(b)$ shot $2766-R e_{E}^{\text {Unit }}=2.36 \times 10^{6} \mathrm{~m}^{-1} ;$ (c) shot 2765 $-R e_{E}^{\text {Unit }}=2.82 \times 10^{6} \mathrm{~m}^{-1}$, shot 2764: (d) $R e_{E}^{\text {Unit }}=2.99 \times 10^{6} \mathrm{~m}^{-1}$.

boundary layer and scaling of the most unstable disturbance frequency with the reciprocal of the boundary-layer thickness.

As the Reynolds number is increased, the flow begins to transition from laminar to turbulent at the downstream detector location. The narrow-band spectral peak in the downstream signal is observed to increase in amplitude and become broader, as shown in figure $6(c)$. With further increases in Reynolds number, as shown in figure $6(d)$, the downstream spectrum increases even further in amplitude, and is spread over a broad range of frequencies with no distinct peaks. This behaviour is consistent with a fluid-dynamic instability increasing in amplitude and then breaking down to turbulence. This conclusion is supported by simultaneous measurements using surface-mounted heat-transfer gauges (Jewell et al. 2011, 2012, 2013a,b; Jewell 2014) which show a corresponding departure from laminar surface heat-flux rates near the downstream detector.

\subsubsection{High-enthalpy conditions}

A second series of shots (2788-2787) was conducted at higher reservoir pressure and reservoir enthalpy $\left(11-13 \mathrm{MJ} \mathrm{kg}^{-1}\right)$ with conditions listed in table 2 . Time traces 

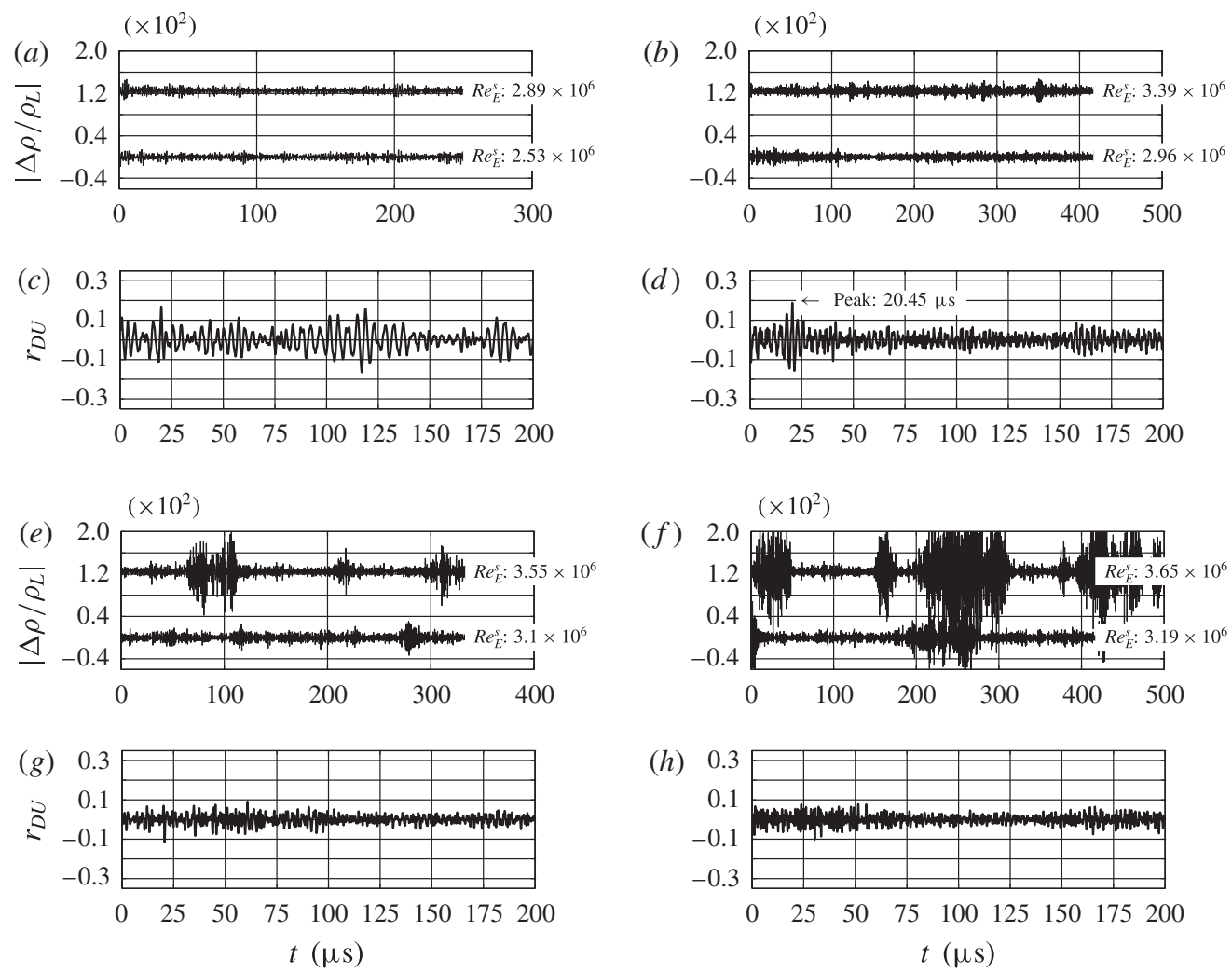

FIGURE 7. $(a, b, e, f)$ Time traces and $(c, d, g, h)$ cross-correlations of $\Delta \rho / \rho_{L}$ for the highenthalpy air shot series. The conditions are summarized in table 2 for each test: $(a, c)$ shot 2788: $R e_{E}^{\text {Unit }}=4.03 \times 10^{6} \mathrm{~m}^{-1},(b, d)$ shot 2789: $R e_{E}^{\text {Unit }}=4.73 \times 10^{6} \mathrm{~m}^{-1},(e, g)$ shot 2790 : $R e_{E}^{\text {Unit }}=4.94 \times 10^{6} \mathrm{~m}^{-1},(f, h)$ shot 2787: $R e_{E}^{\text {Unit }}=5.08 \times 10^{6} \mathrm{~m}^{-1}$.

and correlations are included for these experiments in figure 7, and power spectral density estimates are shown in figure 8. The trends are qualitatively similar to the low-enthalpy series with increasing Reynolds number, resulting in a transition from narrow-band disturbances upstream to broad-band disturbances downstream. Quantitatively, the frequency of the narrow-band disturbances is approximately 1.2 $\mathrm{MHz}$, which required using a smaller window $(10 \mu \mathrm{s})$ in PSD estimates. Although the results are qualitatively similar to the low-enthalpy cases, we found it more difficult to create high-enthalpy test conditions where wavepackets can be observed at both upstream and downstream locations. As a consequence, a distinct wavepacket signature in both locations can be observed only in shot 2789, as shown in figures 7 and $8(b)$. Again, the narrow-band peaks observed in the spectral estimates from the low- and high-enthalpy conditions are consistent with the instability mode first described by Mack (1984), for which an estimate of the most strongly amplified frequency is $f \approx C U_{E} /(2 \delta)$, where $C$ is approximately 0.6 to 0.7 . The observations (table 3) are consistent with the predicted dependence on both boundary-layer thickness and velocity.

\subsection{3. $\mathrm{N}_{2}$ and $\mathrm{CO}_{2}$ cases}

Observations using $\mathrm{N}_{2}$ and $\mathrm{CO}_{2}$ as test gases are summarized in the Appendix as tables 4-7. These results are qualitatively similar in all aspects to those obtained 


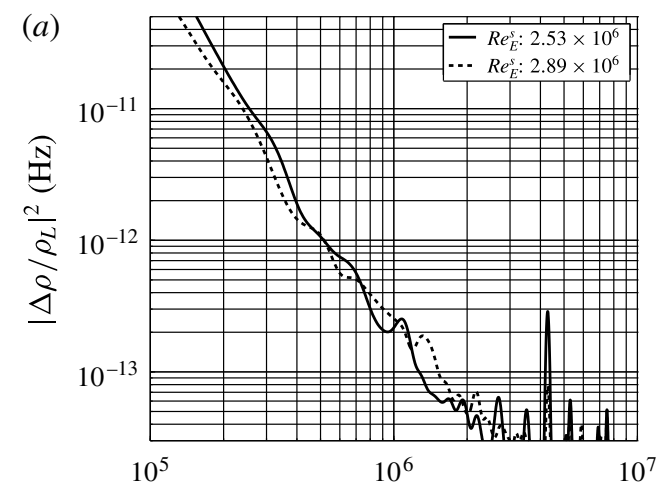

(b)
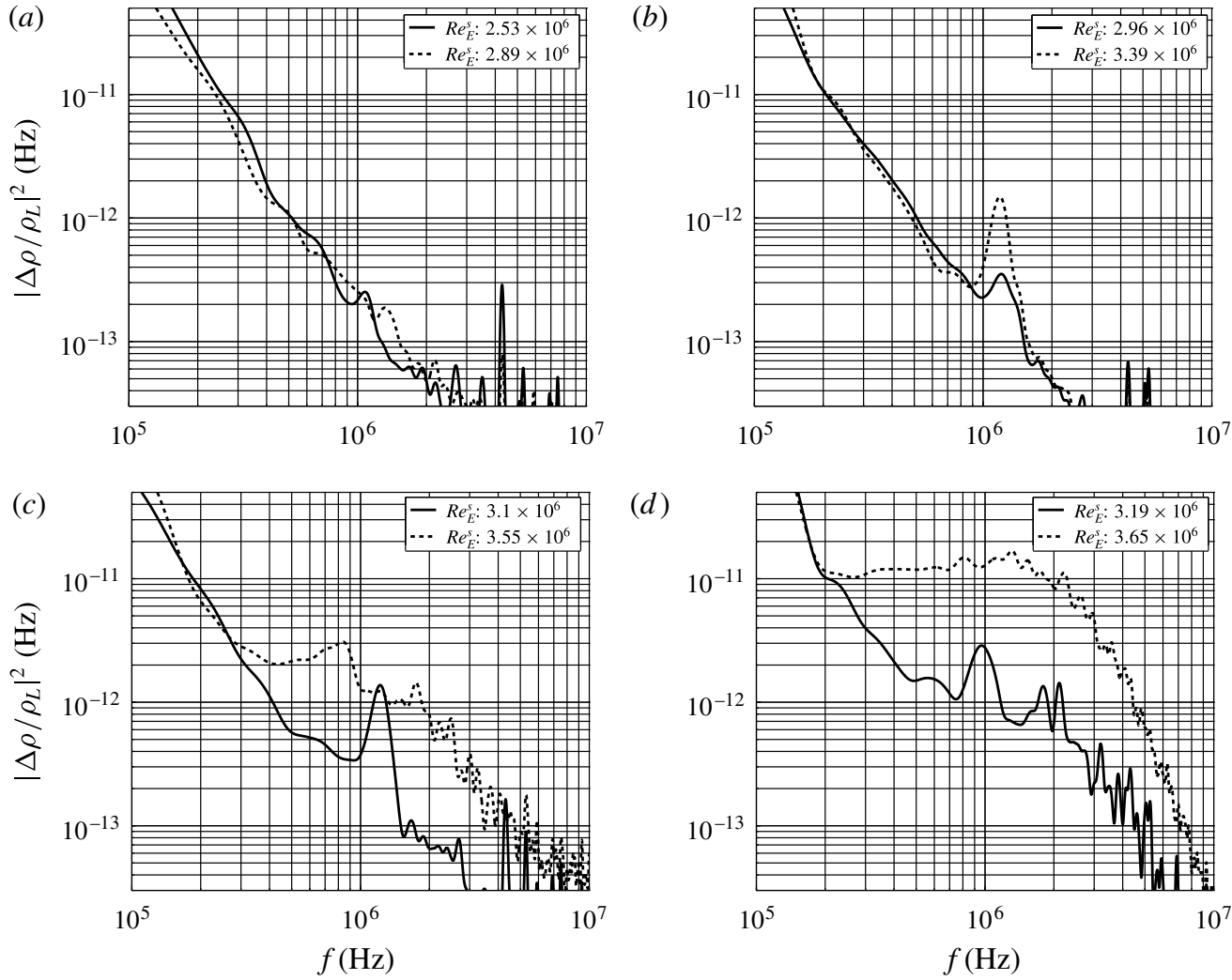

$(d)$

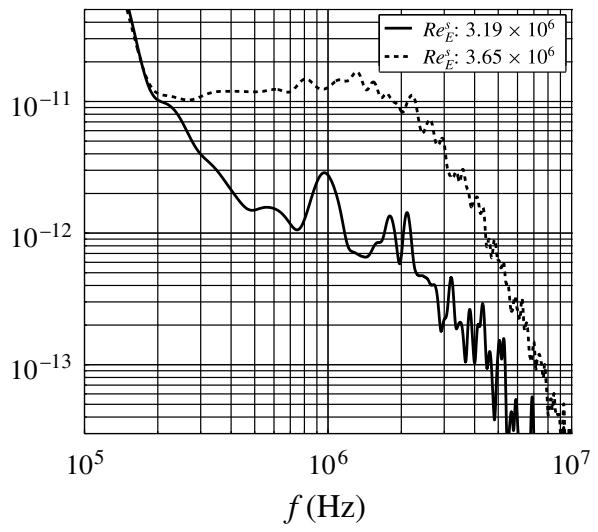

FIgURE 8. Power spectral density estimates of $\Delta \rho / \rho_{L}$ for the high-enthalpy air shot series. The conditions are summarized in table 2 for each of the tests: $(a)$ shot 2788: $R e_{E}^{\text {Unit }}=$ $4.03 \times 10^{6} \mathrm{~m}^{-1},(b)$ shot 2789: $R e_{E}^{\text {Unit }}=4.73 \times 10^{6} \mathrm{~m}^{-1}$, (c) shot 2790: $R e_{E}^{\text {Unit }}=4.94 \times$ $10^{6} \mathrm{~m}^{-1},(d)$ shot 2787: $R e_{E}^{\text {Unit }}=5.08 \times 10^{6} \mathrm{~m}^{-1}$.

with air and exhibit the same quantitative scaling of the spectral peak frequency and cross-correlation of upstream and downstream signals for wavepackets. The thermochemical differences in these flows are in the extent of chemical reaction and vibrational relaxation.

There is minimal dissociation in the $\mathrm{N}_{2}$ free stream, but there is significant vibrational non-equilibrium due to slow exchange of vibrational energy with translational/rotational modes. This results in effective vibrational temperatures that are 800-2000 K higher than the translational/rotational temperature. Three ranges of reservoir enthalpy were investigated for nitrogen (low, medium and high), resulting in a range of flow speeds and non-equilibrium.

There is substantial dissociation $(6-10 \% \mathrm{CO})$ of the $\mathrm{CO}_{2}$ at the shock-tunnel nozzle exit, but the effective temperatures for translation/rotation and vibration are identical due to the rapid rate of energy transfer between these modes. $\mathrm{CO}_{2}$ is unique among the test gases we have examined, as it has the greatest potential for interaction of the second-mode instabilities with the molecular excitation through the energy exchange process. 


\section{Comparison of measured and predicted frequency content}

Linear-stability computations were performed and compared with experimental results. The computations were carried out with PSE-Chem, a part of the STABL software package described in Johnson et al. (1998), Johnson (2000), and Wagnild (2012). The mean flow over the cone is computed by DPLR (Wright et al. 1996); velocity, temperature, and species concentration profiles of the boundary layer are available in chapter 2 of Parziale (2013). The axis-symmetric grid for the computations was generated by the STABL package. There are 360 points in the streamwise and wall-normal directions; increasing this resolution did not yield a significant change to the baseflow. PSE-Chem analyses the mean flow over the cone. First, the method of normal modes is applied to the reacting Navier-Stokes equations, where it is assumed that the boundary layer is quasi-parallel, the gas is in thermochemical non-equilibrium, and the disturbances have the form

$$
q^{\prime}(s, z, t)=\hat{q}(y) \exp (\mathrm{i}(\alpha s+\beta z-\omega t))
$$

where $q^{\prime}$ is a disturbance at a position along the generator of the cone $s$, azimuthal position $z$, and time $t$. The amplitude of the disturbance is considered to be a function of only the wall-normal distance, $\hat{q}=\hat{q}(y)$. The streamwise wavenumber is $\alpha$, the azimuthal wavenumber is $\beta$, and the angular frequency is $\omega$. The spatial linear-stability problem is analysed where the frequency $(\omega)$ is real and the wavenumbers are complex $\left(\alpha=\alpha_{r}+\alpha_{i}\right)$; non-zero azimuthal wavenumbers $(\beta)$ are not considered in this analysis, as the fastest growing disturbance is known to be two-dimensional. The results of linear-stability calculations are then used as initial values for the parabolized stability equation (PSE) analysis, which is used to account for the non-parallel nature of the boundary layer. The procedure for the PSE analysis is found in Johnson (2000), which is built on the work reported in Herbert (1993, 1997) and Chang \& Malik (1994).

Comparisons of computational and experimental results are presented for four experiments in figure 9. For each experiment, there is a computed linear-stability diagram; the range of computed unstable frequencies is shown by the grey scale flood fill plots. The two symbols on each plot are the range of the most amplified frequencies as estimated from power spectra computed from the FLDI measurements.

There is reasonable agreement between the measured peaks in the frequency spectrum of the FLDI data and the calculated most amplified frequencies. The observed frequencies in the air and $\mathrm{CO}_{2}$ cases are systematically lower than the LST predictions at both upstream and downstream locations. If one assumes spatial growth at constant frequency (as is the case in the $N$ factor method), then observed peaks in the frequency spectrum should occur at higher frequencies than the calculated most amplified frequencies because of the history of growth of the packet.

This mismatch of observed and calculated frequency content may indicate that the flow is not truly two-dimensional or that there are nonlinear effects in the evolution of the wavepackets that are not accounted for by conventional LST or PSE methods.

Additionally, the inconsistency of observed and calculated content may be due to systematic error in the computed mean flow conditions at the boundary layer, associated with uncertainties in the run conditions and the physical-chemical models being used for relaxation processes as well as dissociation-recombination reactions. An approximate estimate of the change in most strongly amplified frequency $(f)$ due to a change in static thermodynamic conditions and velocity can be obtained by using the scaling $f \approx U_{E} /(2 \delta)$ and the correlation found for the boundary-layer thickness found in Parziale (2013). Estimating the fractional change in $f$ as 


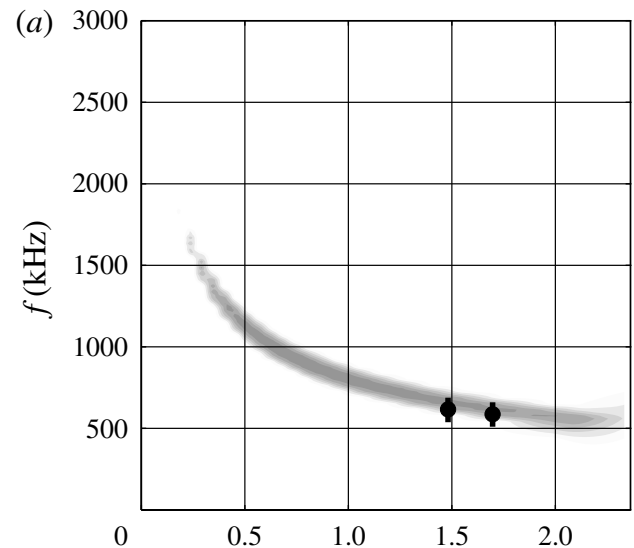

(b)
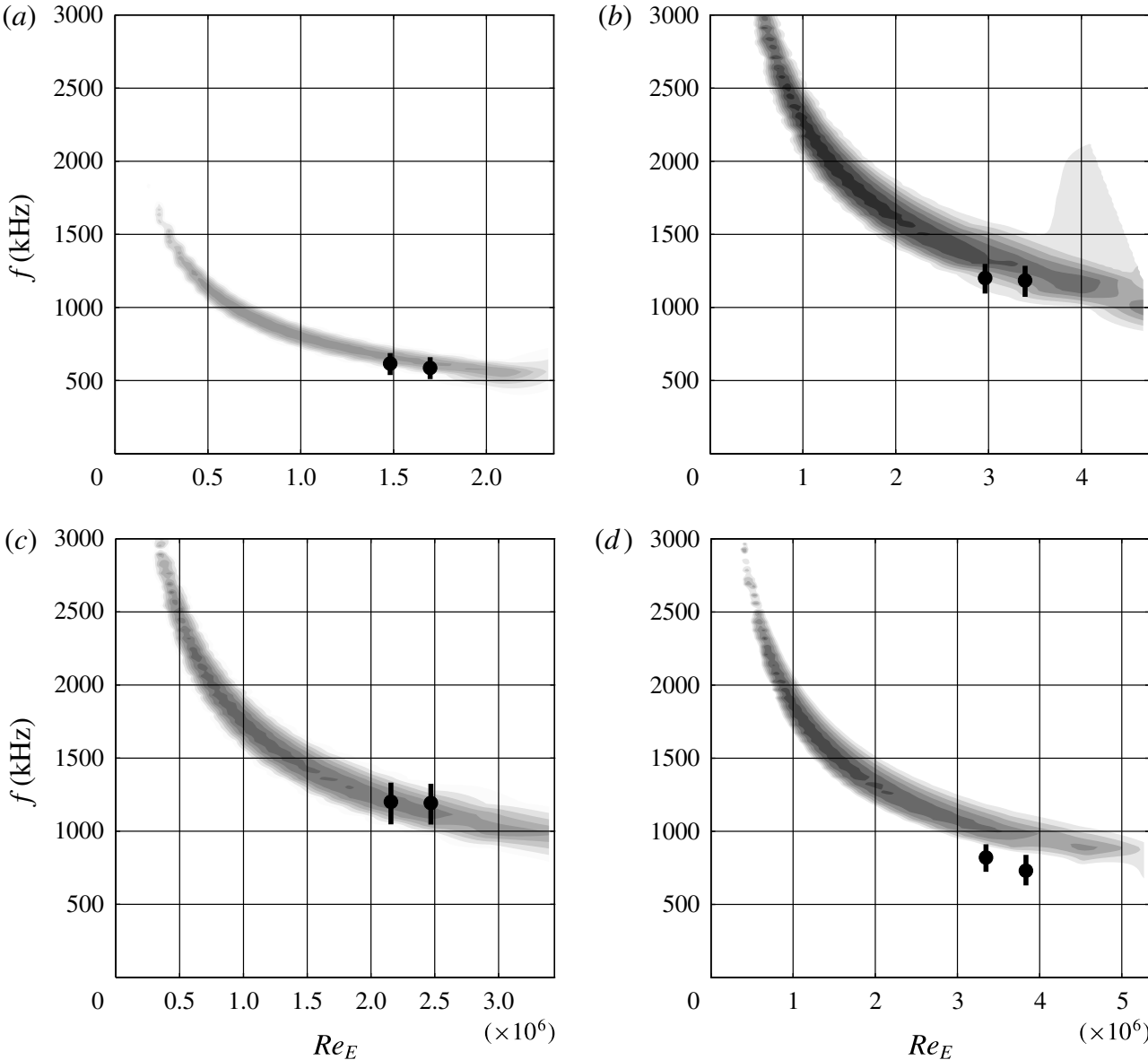

FIgURE 9. Computed linear-stability diagrams and experimental spectra for four selected cases. The shaded area is the unstable region, darker shading indicates larger negative imaginary wavenumber (spatial growth rate). The circular markers represent the maximum in $\Delta \rho / \rho_{L}$ from the PSD estimates, and the black line represents full-width at half-maximum of the peak in the power spectral density: (a) air low enthalpy (shot 2766); (b) air high enthalpy (shot 2789); (c) $\mathrm{N}_{2}$ high enthalpy (shot 2783); (d) $\mathrm{CO}_{2}$ (shot 2796).

$\mathrm{d} f / f=\mathrm{d} \ln f=\mathrm{d} U_{E} / U_{E}-\mathrm{d} \delta / \delta$ results in fractional changes of $\mathrm{d} f / f \approx 15-20 \%$, which could account for some of the systematic shift in the observed frequencies below the predicted LST values.

An additional candidate for the shift in frequency is the effect of a small but nonzero angle of attack. Great care is taken to align the centreline of the cone and the nozzle, but it is impossible to assure that the angle of attack is precisely zero. Hofferth et al. $(2013 a, b)$ show in their testing that a small change in angle of attack can lead to an appreciable change in the most amplified frequency. The possible range in angle of attack for the current set of experiments is estimated to be $0.2^{\circ}$ as measured by a high-precision angle-finding level. Using the correlation of angle of attack versus instability peak frequency from Hofferth et al. $(2013 a, b)$, a $\mathrm{d} f / f \approx 5-10 \%$ change in peak frequency due to the cone misalignment is possible in the present tests. We note that the run conditions in Hofferth et al. $(2013 a, b)$ are at hypersonic conditions with a 

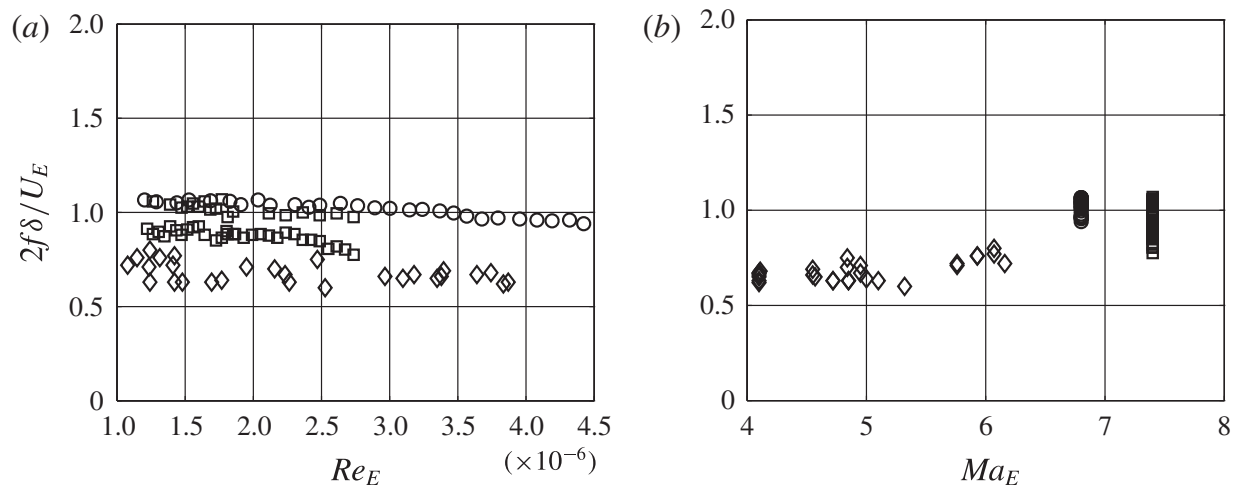

FIGURE 10. Comparison of the measured frequency of the largest amplitude narrow-band disturbances versus the edge Reynolds number based on the distance from the cone tip (a) and edge Mach number $(b)$ with the data from this work (diamonds), Stetson et al. (1983) (circles), and Demetriades (1977) (squares).

free stream Mach number of approximately 6, but at low total enthalpy. The geometry in Hofferth et al. $(2013 a, b)$ is also slightly different, as it is a flared cone.

\section{Frequency content comparison for high-enthalpy and low-enthalpy conditions}

A comparison of the measured frequency $(f)$ of the largest amplitude narrow-band disturbances scaled by the edge velocity $\left(U_{E}\right)$ and the calculated boundary-layer thickness $(\delta)$ versus the edge Reynolds number based on the distance from the cone tip and edge Mach number $M a_{E}$ is presented in figure 10, with the data from this work, Demetriades (1977) and Stetson et al. (1983). The data represent a collection of points over a range of edge Mach number $M a_{E} \approx 4.1-7.4$, edge Reynolds number $\approx 1-4.5 \times 10^{6}$, total enthalpy $\approx 0.5-15 \mathrm{MJ} \mathrm{kg}^{-1}$, wall temperature $\left(T_{W}\right)$ to reservoir temperature $\left(T_{R}\right)$ ratio $T_{W} / T_{R} \approx 0.05-0.8$, in air, $\mathrm{N}_{2}$ and $\mathrm{CO}_{2}$. It is observed here that $2 f \delta / U_{E}$ has a range of $0.6-1.1$ for these conditions.

The scatter in the Demetriades (1977) and Stetson et al. (1983) data is smaller than that of the present work; this is to be expected, as the data from the present work is recorded from reflected-shock-tunnel experiments with a short duration and more uncertainty in run conditions than data from Demetriades (1977) and Stetson et al. (1983), which were collected from conventional hypersonic wind-tunnel experiments. In figure 10 there is a weak dependence of peak frequency on edge Reynolds number for all data sets. The systematic differences in $2 f \delta / U_{E}$ between data sets are due to the substantial differences between the wall temperature ratio and edge Mach number in the Demetriades (1977), Stetson et al. (1983) and T5 tests. This is consistent with the results of LST (Mack 1984), which show that the value of $2 f \delta / U_{E}$ for a given geometry is a function of edge Mach number and boundary-layer temperature profile. The weak dependence on Reynolds number is also consistent with LST, which predicts that the second mode of instability is primarily governed by inviscid considerations.

\section{Schlieren visualization}

High-speed schlieren cinematography from a conventional $z$-type set-up (Settles 2001) is used to record the density disturbances within the boundary layer 

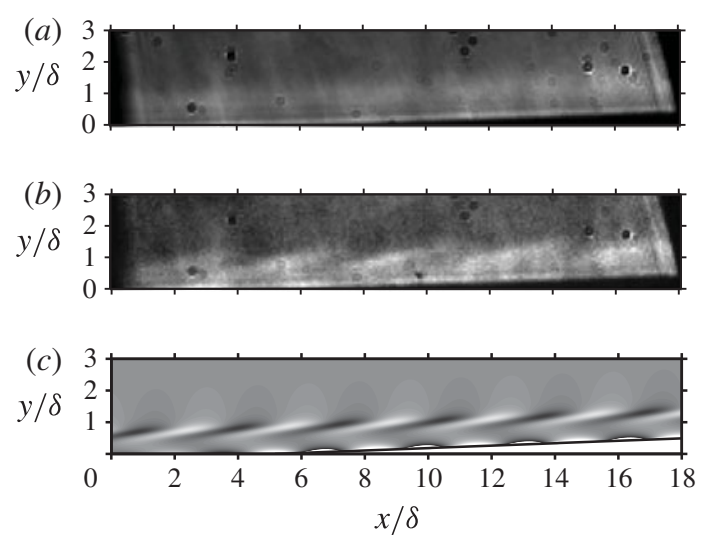

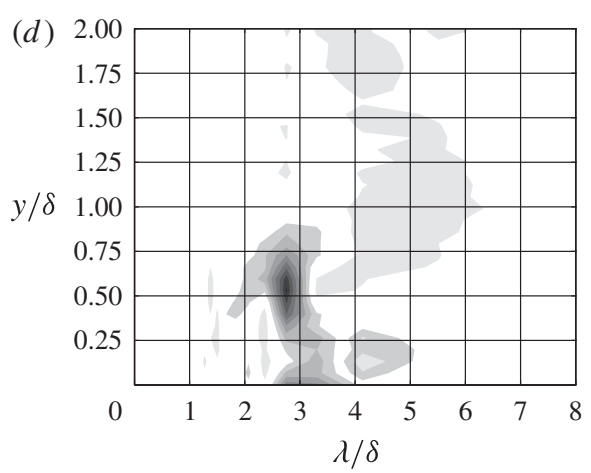

FIgURE 11. (a) Schlieren image from $\mathrm{N}_{2}$ shot 2773 (run conditions in table 4). The image is the mean of ten frames. (b) Single image taken from one frame giving a snapshot of the instability $(t=1312 \mu \mathrm{s})$, where the time indicates the delay from the pressure rise in the reservoir. (c) Synthetic schlieren image created from the density eigenfunctions as computed by linear-stability theory. The flow is from left to right. The calculated boundary-layer thickness (table 5) and calibration of the image magnification prior to the experiment are used to generate the axis labels. (d) Single-sided spatial Fourier transform of the experimental instability snapshot $(b)$ in the streamwise direction.

(figure $11 a-c$ ). The $256 \times 128$ pixel images were recorded at $150 \mathrm{kframes}$ per second with a Vision Research Phantom v710. The light source is a high-power laser diode (905 nm, PN: 905D3S3J09R), pulsed for 12 ns by a LDP-V 50-100 V3 driver module from Laser Components USA, Inc. The centre of the field of view is downstream of both FLDI detectors, approximately $780 \mathrm{~mm}$ from the tip of the cone. Ten frames were selected that bracket a frame in time when an interesting disturbance was observed. An average was constructed of the ten frames (figure 11a), and $75 \%$ of the average is subtracted from each frame for contrast enhancement. During one of these frames, the instability is captured (figure 11b).

Confirmation of the relationship of the observed structures to the density profiles created by the instability was obtained by creating a synthetic schlieren image (figure $11 c$ ) by differentiating the density field shown in figure 1 and representing this as a grey scale image with a threshold simulating the response of the optical system. The synthetic image (figure 11c) show structures that are similar to the experimental result (figure 11c). Note that the tilted structures visible in the schlieren images correspond to the density fluctuations shown in figure 1 near the edge of the boundary layer, $y \sim \delta_{.99}$. An even stronger set of density fluctuations are visible in figure 1 close to the wall, $y \sim 0$, but, due to the limitations of the optical system, the near-wall disturbances cannot be imaged.

The wavelength in the experimental result is determined by a single-sided amplitude spectrum (figure $11 d$ ) of the image brightness in figure $11(b)$ in the streamwise direction. The most amplified wavelength is $\lambda / \delta \approx 2.9$, and occurs at a maximum of approximately $60 \%$ of the boundary-layer thickness. Linear-stability theory calculations (Bitter \& Shepherd 2014) indicate a comparable most amplified wavelength of $\lambda / \delta \approx 3.2$. The structures of the instability are inclined at an $11-15^{\circ}$ angle to the surface in the experimental result (figure 11b). This angle is similar to, but smaller than the results reported in Kimmel et al. (1996), VanDercreek (2010) 
and Laurence et al. (2012, 2014a,b). The angle of the structures in the synthetic schlieren image (figure $11 \mathrm{c}$ ) are inclined at a $10-13^{\circ}$ angle to the cone surface.

\section{Conclusions}

The focused laser differential interferometer (FLDI) was used to measure the instability waves prior to transition to turbulent flow at hypervelocity conditions on a slender body in the T5 reflected-shock tunnel. The frequency of the dominant instability observed in this work is in reasonable agreement with previous steady-flow hypersonic wind-tunnel testing in which the second mode was found to dominate transition. Boundary-layer stability analysis was performed and the results show reasonable agreement between the calculated most amplified frequency and measured spectral peaks in the FLDI signals. In addition, comparison of high-speed schlieren visualization with synthetic images derived from linear-stability theory are in good agreement.

We conclude that second-mode instability may be studied at hypervelocity conditions in a reflected-shock tunnel, despite the experimental difficulties. At the outset of this work, it was not clear if unknown 'bypass' transition mechanisms would dominate. This would have been a fundamental experimental flaw that would have precluded the examination of instability and transition in a reflected-shock tunnel. Additionally, experiment-to-experiment repeatability concerns were addressed with a facility cleaning regimen. For example, see figure $6(b, c)$. The edge Reynolds number in the downstream detector of figure $6(b)$ nearly matches the edge Reynolds number at the upstream detector in figure $6(c)$; the amplitude of the measured disturbance is also nearly the same, indicating repeatability.

We identify the level of disagreement between the stability analysis and measurements as a topic of future work. Reconciling the predicted and measured frequency content will require considering both the theoretical basis of the computations as well as the sensitivity of the stability-calculation results to the base flow and tunnel conditions. Similar issues have been reported in cold-flow hypersonic facilities where run-condition calculation is less complex and experimental measurement difficulties are more tractable. Researchers are making significant progress in comparing experimental and computational instability growth for cold-flow hypersonics (Marineau et al. 2015), and we expect those advances to also be of value in hypervelocity flow.

\section{Acknowledgements}

The authors thank B. Valiferdowsi and J. Jewell for their assistance in operating and maintaining T5. We are particularly grateful to G. Candler and H. Johnson for generously providing their software and to $\mathrm{R}$. Wagnild for his invaluable help in using these programs. N. Bitter provided key insights into stability theory as well as carried out independent analysis and computations for figures 1 and 11 (the synthetic schlieren images). This work is based in part on the $\mathrm{PhD}$ dissertation of the first author Parziale (2013), and was an activity that was part of National Center for Hypersonic Laminar-Turbulent Research, sponsored by the 'Integrated Theoretical, Computational, and Experimental Studies for Transition Estimation and Control' project supported by the US Air Force Office of Scientific Research and the National Aeronautics and Space Administration (FA9552-09-1-0341). 
Appendix. Conditions and scaling for $\mathrm{N}_{2}$ and $\mathrm{CO}_{2}$ tests

\begin{tabular}{lccccccccc} 
Shot & $\begin{array}{c}U_{E} \\
\left(\mathrm{~m} \mathrm{~s}^{-1}\right)\end{array}$ & $\begin{array}{c}\rho_{E} \\
\left(\mathrm{~kg} \mathrm{~m}^{-3}\right)\end{array}$ & $\begin{array}{c}P_{E} \\
(\mathrm{kPa})\end{array}$ & $\begin{array}{c}T_{t / r E} \\
(\mathrm{~K})\end{array}$ & $\begin{array}{c}T_{v E} \\
(\mathrm{~K})\end{array}$ & $\begin{array}{c}M a_{E} \\
(-)\end{array}$ & $\begin{array}{c}\operatorname{Re}_{E}^{\text {Unit }} \\
\left(\mathrm{m}^{-1}\right)\end{array}$ & $\begin{array}{c}Y_{\mathrm{N}_{2}} \\
(-)\end{array}$ & $\begin{array}{c}Y_{\mathrm{N}} \\
(-)\end{array}$ \\
\hline 2774 & 4054 & 0.020 & 6.9 & 1183 & 3303 & 5.76 & $1.72 \times 10^{6}$ & 0.99 & 0.01 \\
2773 & 3859 & 0.020 & 6.0 & 1014 & 3136 & 5.93 & $1.83 \times 10^{6}$ & 1.00 & 0.00 \\
2772 & 3665 & 0.021 & 5.4 & 876 & 3012 & 6.07 & $1.98 \times 10^{6}$ & 1.00 & 0.00 \\
2775 & 3511 & 0.023 & 5.4 & 781 & 2924 & 6.16 & $2.25 \times 10^{6}$ & 1.00 & 0.00 \\
2781 & 4793 & 0.045 & 29.8 & 2222 & 3360 & 4.95 & $3.11 \times 10^{6}$ & 0.99 & 0.01 \\
2780 & 4624 & 0.049 & 28.7 & 1959 & 3300 & 5.10 & $3.61 \times 10^{6}$ & 0.99 & 0.01 \\
2779 & 4389 & 0.050 & 24.4 & 1630 & 3200 & 5.32 & $4.03 \times 10^{6}$ & 1.00 & 0.00 \\
2778 & 4194 & 0.050 & 20.3 & 1373 & 3082 & 5.54 & $4.15 \times 10^{6}$ & 1.00 & 0.00 \\
2783 & 4917 & 0.052 & 38.1 & 2446 & 3263 & 4.84 & $3.44 \times 10^{6}$ & 0.99 & 0.01 \\
2782 & 4792 & 0.056 & 37.1 & 2233 & 3252 & 4.95 & $3.85 \times 10^{6}$ & 0.99 & 0.01
\end{tabular}

TABLE $4 . \mathrm{N}_{2}$ boundary-layer edge conditions.

Shot $\begin{array}{llllllllll}M a_{E} & U_{E} & \tau & U_{E} /(\Delta s / \tau) & \delta_{U} & f_{U} & 2 f_{U} \delta_{U} / U_{E} & \delta_{D} & f_{D} & 2 f_{D} \delta_{D} / U_{E}\end{array}$

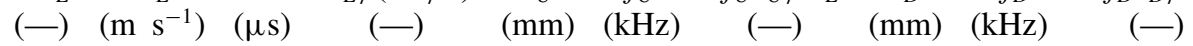

\begin{tabular}{lcccccccccc}
\hline 2774 & 5.76 & 4054 & 21.6 & 0.96 & 2.37 & 620 & 0.72 & 2.54 & 570 & 0.71 \\
2773 & 5.93 & 3859 & 24.6 & 1.04 & 2.37 & 620 & 0.76 & 2.53 & 580 & 0.76 \\
2772 & 6.07 & 3665 & 25.3 & 1.02 & 2.32 & 630 & 0.80 & 2.49 & 570 & 0.77 \\
2775 & 6.16 & 3511 & - & - & 2.22 & 570 & 0.72 & 2.38 & - & - \\
2781 & 4.95 & 4793 & 18.1 & 0.95 & 1.56 & 1100 & 0.71 & 1.67 & 960 & 0.67 \\
2780 & 5.10 & 4624 & 18.8 & 0.96 & 1.48 & 980 & 0.63 & 1.58 & - & - \\
2779 & 5.32 & 4389 & - & - & 1.46 & 900 & 0.60 & 1.57 & - & - \\
2778 & 5.54 & 4194 & - & - & 1.48 & - & - & 1.58 & - & - \\
2783 & 4.84 & 4917 & 18.4 & 0.99 & 1.44 & 1200 & 0.70 & 1.54 & 1200 & 0.75 \\
2782 & 4.95 & 4792 & - & - & 1.40 & - & - & 1.49 & - & -
\end{tabular}

TABLE 5. $\mathrm{N}_{2}$ Boundary-layer instability parameters and scaling.

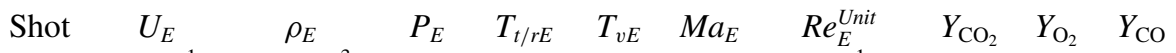

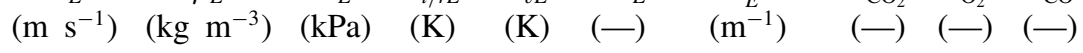

\begin{tabular}{lllllllllll}
\hline 2795 & 2549 & 0.086 & 23.6 & 1356 & 1356 & 4.10 & $5.07 \times 10^{6}$ & 0.85 & 0.06 & 0.10 \\
2796 & 2518 & 0.090 & 24.2 & 1331 & 1331 & 4.10 & $5.34 \times 10^{6}$ & 0.86 & 0.05 & 0.09 \\
2794 & 2512 & 0.091 & 24.3 & 1327 & 1327 & 4.10 & $5.39 \times 10^{6}$ & 0.86 & 0.05 & 0.09 \\
2793 & 2398 & 0.098 & 24.0 & 1227 & 1227 & 4.11 & $5.97 \times 10^{6}$ & 0.90 & 0.04 & 0.06
\end{tabular}

TABLE $6 . \mathrm{CO}_{2}$ boundary-layer edge conditions. 


\begin{tabular}{ccccccccccc} 
Shot & $\begin{array}{c}M a_{E} \\
(-)\end{array}$ & $\begin{array}{c}U_{E} \\
\left(\mathrm{~m} \mathrm{~s}^{-1}\right)\end{array}$ & $\begin{array}{c}\tau \\
(\mu \mathrm{s})\end{array}$ & $\begin{array}{c}U_{E} /(\Delta s / \tau) \\
(-)\end{array}$ & $\begin{array}{c}\delta_{U} \\
(\mathrm{~mm})\end{array}$ & $\begin{array}{c}f_{U} \\
(\mathrm{kHz})\end{array}$ & $\begin{array}{c}2 f_{U} \delta_{U} / U_{E} \\
(-)\end{array}$ & $\begin{array}{c}\delta_{D} \\
(\mathrm{~mm})\end{array}$ & $\begin{array}{c}f_{D} \\
(\mathrm{kHz})\end{array}$ & $\begin{array}{c}2 f_{D} \delta_{D} / U_{E} \\
(-)\end{array}$ \\
\hline 2795 & 4.10 & 2549 & 30.7 & 0.86 & 1.02 & 840 & 0.67 & 1.10 & 780 & 0.67 \\
2796 & 4.10 & 2518 & 31.3 & 0.87 & 0.99 & 820 & 0.65 & 1.06 & 730 & 0.62 \\
2794 & 4.10 & 2512 & 31.9 & 0.88 & 0.99 & 840 & 0.66 & 1.06 & 750 & 0.63 \\
2793 & 4.11 & 2398 & - & - & 0.95 & 860 & 0.68 & 1.01 & - & -
\end{tabular}

TABLE 7. $\mathrm{CO}_{2}$ boundary-layer instability parameters and scaling.

\section{REFERENCES}

AdAM, P. H. \& Hornung, H. G. 1997 Enthalpy effects on hypervelocity boundary-layer transition: ground test and flight data. J. Spacecr. Rockets 34 (5), 614-619.

Azzazy, M., Modarress, D. \& HoefT, T. 1987 High-sensitivity density fluctuation detector. J. Phys. E: Sci. Instrum. 20 (4), 428-431.

BERRIDGE, D. C. 2010 Measurements of second-mode instability waves in hypersonic boundary layers with a high-frequency pressure transducer. Master's thesis, Purdue University.

BitTer, N. P. \& SHEPherd, J. E. 2014. Transient growth in hypersonic boundary layers. 7th AIAA Theoretical Fluid Mechanics Conference, Atlanta GA, June 2014, AIAA Paper 2014-2497.

BItTer, N. P. 2015 Stability of hypervelocity boundary layers. PhD thesis, California Institute of Technology, California, USA.

BOEDEKER, L. R. 1959 Analysis and construction of a sharp focusing schlieren system. Master's thesis, Massachusetts Institute of Technology, Massachusetts.

CANDler, G. V. 2005 Hypersonic nozzle analysis using an excluded volume equation of state. In Proceedings of 38th AIAA Thermophysics Conference, Toronto, Ontario, Canada, AIAA-20055202.

CASPER, K. M. 2009 Hypersonic wind-tunnel measurements of boundary-layer pressure fluctuations. Master's thesis, Purdue University.

Chang, C.-L. \& MALiK, M. R. 1994 Oblique-mode breakdown and secondary instability in supersonic boundary layers. J. Fluid Mech. 273 (1), 323-360.

Coleman, H. W. \& Steele, W. G. 1999 Experimentation and Uncertainty Analysis for Engineers, 2nd edn. John Wiley and Sons, Inc.

Demetriades, A. 1977 Laminar boundary layer stability measurements at Mach 7 including wall temperature effects. AFOSR-TR-77-1311.

Fedorov, A. 2011 Transition and stability of high-speed boundary layers. Annu. Rev. Fluid Mech. 43, 79-95.

Fedorov, A. \& Tumin, A. 2011 High-speed boundary-layer instability: old terminology and a new framework. AIAA J. 49, 1647-1657.

FUJII, K. 2006 Experiment of the two-dimensional roughness effect on hypersonic boundary-layer transition. J. Spacecr. Rockets 43 (4), 731-738.

Fujit, K., Noriaki, H., Tadao, K., Shoichi, T., Muneyoshi, N., Yukihiro, I., Akihiro, N. \& Hiroshi, O. 2011 A measurement of instability wave in the hypersonic boundary layer on a sharp cone. In Proceedings of the 41st AIAA Fluid Dynamics Conference and Exhibit, Honolulu, Hawaii, AIAA-2011-3871.

GARG, S. \& Settles, G. S. 1998 Measurements of a supersonic turbulent boundary layer by focusing schlieren deflectometry. Exp. Fluids 25 (3), 254-264.

Germain, P. D. \& Hornung, H. G. 1997 Transition on a slender cone in hypervelocity flow. Exp. Fluids 22, 183-190.

Gronvall, J. E., Johnson, H. B. \& CAndler, G. V. 2014 Boundary-layer stability analysis of high enthalpy shock tunnel transition experiments. J. Spacecr. Rockets 51, 455-467. 
Heitmann, D., Kähler, C., Radespiel, R., Rödiger, T., Knauss, H. \& Wagner, S. 2011 Non-intrusive generation of instability waves in a planar hypersonic boundary layer. Exp. Fluids 50, 457-464.

Herbert, T. 1993 Parabolized stability equations. AGARD-R-793.

Herbert, T. 1997 Parabolized stability equations. Annu. Rev. Fluid Mech. 29 (1), 245-283.

Hofferth, J. W., Humble, R. A., Floryan, D. C. \& Saric, W. S. $2013 a$ High-bandwidth optical measurements of the second-mode instability in a Mach 6 quiet tunnel. In Proceedings of 51st AIAA Aerospace Sciences Meeting Including the New Horizons Forum and Aerospace Exposition, Grapevine, Texas, AIAA 2013-0378.

Hofferth, J. W., Saric, W., Kuehl, J., Perez, E., Kocian, T. \& Reed, H. 2013b Boundary layer instability and transition on a flared cone in a Mach 6 quiet wind tunnel. Intl J. Engng Syst. Model. Simul. 5 (1), 109-124.

Hornung, H. G. 1993 Experimental hypervelocity flow simulation, needs, achievements and limitations. In Proceedings of the First Pacific International Conference on Aero Sc. and Tech., Taiwan.

JEWELL, J. S. 2014 Boundary-layer transition on a slender cone in hypervelocity flow with real gas effects. PhD thesis, California Institute of Technology.

Jewell, J. S., Leyva, I. A., Parziale, N. J. \& Shepherd, J. E. 2011 Effect of gas injection on transition in hypervelocity boundary layers. In Proceedings of the 28th International Symposium on Shock Waves, Manchester, UK, ISSW.

Jewell, J. S., Parziale, N. J., Leyva, I. A., Shepherd, J. E. \& Hornung, H. G. 2012 Turbulent spot observations within a hypervelocity boundary layer on a 5-degree half-angle cone. In Proceedings of 42nd AIAA Fluid Dynamics Conference and Exhibit, New Orleans, Louisiana, AIAA-2012-3062.

Jewell, J. S., Shepherd, J. E. \& LeYva, I. A. $2013 a$ Shock tunnel operation and correlation of boundary layer transition on a cone in hypervelocity flow. In Proceedings of the 29th International Symposium on Shock Waves, Madison, WI, ISSW.

Jewell, J. S., Wagnild, R. M., Leyva, I. A., CAndler, G. V. \& Shepherd, J. E. $2013 b$ Transition within a hypervelocity boundary layer on a 5-degree half-angle cone in air/ $\mathrm{CO}_{2}$ mixtures. In 51st AIAA Aerospace Sciences Meeting including the New Horizons Forum and Aerospace Exposition, Grapevine, Texas, AIAA-2013-0523.

Johnson, H. B. 2000 Thermochemical interactions in hypersonic boundary layer stability. PhD thesis, University of Minnesota.

Johnson, H. B., SeIPP, T. G \& CAndler, G. V. 1998 Numerical study of hypersonic reacting boundary layer transition on cones. Phys. Fluids 10 (13), 2676-2685.

KendaLl, J. M. 1975 Wind-tunnel experiments relating to supersonic and hypersonic boundary-layer transition. AIAA J. 13 (3), 290-299.

Kimmel, R. L., Demetriades, A. \& Donaldson, J. C. 1996 Space-time correlation measurements in a hypersonic transitional boundary layer. AIAA J. 34 (12), 2484-2489.

Laderman, A. J. \& Demetriades, A. 1976 Detection of boundary-layer-transition with a laserbeam. AIAA J. 14 (1), 102-104.

LAU, K. Y. 2008 Hypersonic boundary-layer transition: application to high-speed vehicle design. J. Spacecr. Rockets 45 (2), 176-183.

Laurence, S. J., Wagner, A. \& Hannemann, K. $2014 a$ Schlieren-based techniques for investigating instability development and transition in a hypersonic boundary layer. Exp. Fluids 55 (8), 1782.

Laurence, S. J., Wagner, A., Hannemann, K., Wartemann, V., Lüdeke, H., Tanno, H. \& IтоH, K. 2012 Time-resolved visualization of instability waves in a hypersonic boundary layer. AIAA J. 50 (6), 243-246.

Laurence, S. J., Wagner, A., Ozawa, H., Schramm, J. M. \& Hannemann, K. $2014 b$ Visualization of a hypersonic boundary-layer transition on a slender cone. In 19th AIAA International Space Planes and Hypersonic Systems and Technologies Conference, Atlanta, Georgia, AIAA-2014-3110. 
LEES, L. \& LIN, C. C. 1946 Investigation of the stability of the laminar boundary layer in a compressible fluid. Tech. Rep. Technical Note 1155.

LIN, T. C. 2008 Influence of laminar boundary-layer transition on entry vehicle designs. J. Spacecr. Rockets 45 (2), 165-175.

MACK, L. M. 1975 Linear stability theory and the problem of supersonic boundary-layer transition. AIAA 13 (3), 278-289.

MACK, L. M. 1984 Boundary-layer linear stability theory. AGARD Rep 709.

MACK, L. M. 1999 Early history of compressible linear stability theory. In Laminar-Turbulent Transition (ed. H. Fasel \& W. S. Saric), pp. 247-299. Springer.

Marineau, E. C., Moraru, G. C., Lewis, D. R., Norris, J. D., Lafferty, J. D. \& Johnson, H. B. 2015 Investigation of Mach 10 boundary layer stability of sharp cones at angle-of-attack, part 1: experiments. In Proceedings of AIAA SciTech 2015, Kissimmee, Florida, AIAA-20151737.

MCQuARrie, D. 2000 Statistical Mechanics. University Science Books.

O'HARE, J. E. 1985 A nonperturbing boundary-layer transition detector. In Proceedings of SPIE 0569, High Speed Photography, Videography, and Photonics III. San Diego, California, pp. 58-63.

Parziale, N. J. 2013 Slender-body hypervelocity boundary-layer instability. PhD thesis, California Institute of Technology.

Parziale, N. J., Jewell, J. S., Shepherd, J. E. \& Hornung, H. G. 2011 Shock tunnel noise measurement with resonantly enhanced focused schlieren deflectometry. In Proceedings of the 28th International Symposium on Shock Waves, Manchester, UK, ISSW.

Parziale, N. J., Shepherd, J. E. \& Hornung, H. G. $2013 a$ Differential interferometric measurement of instability at two points in a hypervelocity boundary layer. In Proceedings of 51st AIAA Aerospace Sciences Meeting Including the New Horizons Forum and Aerospace Exposition, Grapevine, Texas, AIAA-2013-0521.

Parziale, N. J., Shepherd, J. E. \& Hornung, H. G. $2013 b$ Differential interferometric measurement of instability in a hypervelocity boundary layer. AIAA J. 51 (3), 750-754.

Parziale, N. J., Shepherd, J. E. \& Hornung, H. G. 2014 Free-stream density perturbations in a reflected-shock tunnel. Exp. Fluids 55 (2), 1665-1668.

Rasheed, A., Hornung, H. G., Fedorov, A. V. \& Malmuth, N. D. 2002 Experiments on passive hypervelocity boundary-layer control using an ultrasonically absorptive surface. AIAA $J$. 40 (3), 481-489.

Reshotko, E. 2008 Transition issues for atmospheric entry. J. Spacecr. Rockets 45 (2), 161-164.

Roediger, T., Knauss, H., Estorf, M., Schneider, S. P. \& Smorodsky, B. V. 2009 Hypersonic instability waves measured using fast-response heat-flux gauges. J. Spacecr. Rockets 46 (2), 266-273.

Roediger, T., Knauss, H., Gaisbauer, Uwe, Kraemer, E., Jenkins, S. \& von Wolfersdorf, J. 2008 Time-resolved heat transfer measurements on the tip wall of a ribbed channel using a novel heat flux sensor, part I. Sensor and benchmarks. J. Turbomach. 130 (1), 011018.

RotTA, N. R. 1966 Effects of nose bluntness on the boundary layer characteristics of conical bodies at hypersonic speeds. AD-0645668 or NYU-AA-66-66.

Salyer, T. R., Collicott, S. H. \& Schneider, S. P. 2006 Characterizing Laser-Generated Hot Spots for Receptivity Studies, vol. 44, pp. 2871-2878.

SARIC, W. S., ReED, H. L. \& Kerschen, E. J. 2002 Boundary layer receptivity to freestream disturbances. Annu. Rev. Fluid Mech. 34, 291-319.

Schlichting, H. 1933 Zur Entstehung der Turbulenz bei der Plattenströmung. In Nachrichten von der Gesellschaft der Wissenschaften zu Göttingen: Mathematisch-Physikalische Klasse, pp. 181-208. See also: ZAMM vol. 13, 171-174 (1933).

SChmisseur, J. D. \& ERBland, P. 2012 Introduction: assessment of aerothermodynamic flight prediction tools through ground and flight experimentation. Prog. Aerosp. Sci. 48-49, 2-7.

SCHNEIDER, S. P. 2001 Effects of high-speed tunnel noise on laminar-turbulent transition. J. Spacecr. Rockets 38 (3), 323-333. 
SCHNEIDER, S. P. 2004 Hypersonic laminar-turbulent transition on circular cones and scramjet forebodies. Prog. Aerosp. Sci. 40 (1-2), 1-50.

SCHNEIDER, S. P. 2008 Development of hypersonic quiet tunnels. J. Spacecr. Rockets 45 (4), 641-664.

Schubauer, G. B. \& SKRAMSTAD, H. K. 1948 Laminar-boundary-layer oscillations and transition on a flat plate, NACA-TR-909.

Settles, G. S. 2001 Schlieren and Shadowgraph Techniques, 1st edn. Springer.

SMEETS, G. 1972 Laser interferometer for high sensitivity measurements on transient phase objects. IEEE Trans. Aerosp. Electron. Syst. 8 (2), 186-190.

SMEETS, G. 1973 Laser-Interferometer mit grossen, fokussierten Lichtbündeln für lokale Messungen, ISL - N11/73.

SmeEts, G. 1974 Verwendung eines Laser-Differentialinterferometers zur Bestimmung lokaler Schwankungsgrössen sowie des mittleren Dichteprofils in cinem turbulenten Freistrahl, ISL N20/74.

Smeets, G. 1977 Flow diagnostics by laser interferometry. IEEE Trans. Aerosp. Electron. Syst. AES-13 (2), 82-90.

Smeets, G. \& George, A. 1973 Anwendungen des Laser-Differential interferometers in der Gasdynamik, ISL - N28/73, Also translated by Goetz, A.: ADA-307459.

StAlKer, R. J. 1989 Hypervelocity aerodynamics with chemical nonequilibrium. Annu. Rev. Fluid Mech. 21, 37-60.

Stetson, K. F. 1983 Nosetip bluntness effects on cone frustum boundary layer transition in hypersonic flow. In Proceedings of the AlAA 16th Fluid and Plasma Dynamics Conference, Danvers, Massachusetts, AIAA-83-1763.

Stetson, K. F., Donaldson, J. C. \& Siler, L. G. 1984 Laminar boundary layer stability experiments on a cone at Mach 8, part 2: blunt cone. In Proceedings of the 22nd AIAA Aerospace Sciences Meeting, Reno, Nevada, AIAA-84-0006.

Stetson, K. F., Thompson, E. R., Donaldson, J. C. \& Siler, L. G. 1983 Laminar boundary layer stability experiments on a cone at Mach 8, part 1: sharp cone. In Proceedings of the AlAA 16th Fluid and Plasma Dynamics Conference, Danvers, Massachusetts, AIAA-83-1761.

Stetson, K. F., Thompson, E. R., Donaldson, J. C. \& Siler, L. G. 1989 Laminar boundary layer stability experiments on a cone at Mach 8, part 5: tests with a cooled model. In Proceedings of the AlAA 20th Fluid and Plasma Dynamics Conference, Buffalo, New York, AIAA-89-1895.

Tanno, H., Komura, T., Sato, K., Itoh, K., Takahashi, M. \& Fujil, K. 2009 Measurements of hypersonic boundary layer transition on cone models in the free-piston shock tunnel HIEST. In Proceedings of 47th AIAA Aerospace Sciences Meeting including The New Horizons Forum and Aerospace Exposition, Orlando, FL, AIAA.

TOLLMIEN, W. 1929 Über die Entstehung der Turbulenz, also translated as the production of turbulence, 1931, NACA-TM-609.

VAnDercreeK, C. P. 2010 Hypersonic application of focused schlieren and deflectometry. PhD thesis, University of Maryland, College Park, Maryland.

VanDercreek, C. P., Smith, M. S. \& YU, K. H. 2010 Focused Schlieren and Deflectometry at AEDC Hypervelocity Wind Tunnel No. 9. In Proceedings of 27th AIAA Aerodynamic Measurement Technology and Ground Testing Conference, Chicago, Illinois. AIAA 2010-4209.

WAGNILD, R. M. 2012 High enthalpy effects on two boundary layer disturbances in supersonic and hypersonic flow. $\mathrm{PhD}$ thesis, University of Minnesota.

Weinstein, L. M. 1993 Large-field high-brightness focusing schlieren system. AIAA J. 31 (7), $1250-1255$.

Wright, M. J., Candler, G. V. \& Prampolini, M. 1996 Data-parallel lower-upper relaxation method for the Navier-Stokes equations. AIAA J. 34 (7), 1371-1377.

Zhong, X.\& WANG, X. 2012 Direct numerical simulation on the receptivity, instability, and transition of hypersonic boundary layers. Annu. Rev. Fluid Mech. 44, 527-561. 